\title{
$C(t)$ dominance of the mixed I/II creep crack: Part I. Transient creep
}

\author{
Yanwei Dai ${ }^{\mathrm{a}, *}$, Yinghua Liu ${ }^{\mathrm{b}}$, Fei Qin ${ }^{\mathrm{a}}$, Guian Qian ${ }^{\mathrm{c}}$, Yuh J. Chao ${ }^{\mathrm{d}}$ \\ ${ }^{a}$ College of Mechanical Engineering and Applied Electronics Technology, Beijing University of Technology, Beijing 100124, China \\ ${ }^{\mathrm{b}}$ Department of Engineering Mechanics, AML, Tsinghua University, Beijing 100084, China \\ ${ }^{\mathrm{c}}$ Institute of Mechanics, Chinese Academy of Sciences, China \\ ${ }^{\mathrm{d}}$ University of South Carolina, 300 Main Street, Room A123, Columbia, SC 29208, USA
}

\section{A R T I C L E I N F O}

\section{Keywords:}

$C(\mathrm{t})$-integral

Constraint effect

T-stress

Mixed I/II

Transient creep

\begin{abstract}
A B S T R A C T
The mixed type crack is common to be found in engineering practices, however, the characteristics of mixed I/II creep crack tip fields have not been studied thoroughly. The aim of this part of the paper is to study the dominance of $C(t)$-integral for mixed I/II type creep crack tip field under transient creep. The boundary layer model is presented to investigate the dominance of $C(t)$ under various mixed mode cases. For transient mixed mode creep crack under boundary layer model, $C(t)$-integral is related with the effective stress intensity factor (SIF). The near field of mixed creep crack tip field can be influenced by the remote $T$-stress greatly. The maximum tangential stress direction also can be influenced if the remote $T$-stress level is large enough. The loss dominance of the $C(t)$ presents more remarkable under negative stress under transient creep. The relations of creep mixity factor with remote elastic mixity factor of the boundary layer model is also presented. The $T$-stress effects on the constraint parameter $Q^{\prime}$ and $Q^{*}$ are presented. The case that near the pure mode I case presents the most significant loss of constraint compared with the other mixed mode cases. The comparison between the sharp crack and blunted crack is made, and the sharpening effect is found be existed in the pure mode II case which reveals that the situation of mode II case may have a more severe damage process than that of mode I case.
\end{abstract}

\section{Introduction}

Estimation of creep crack tip field accurately is a foundation to make better prediction of the service lifetime for flaw contained structures operated at high temperature. The potential influence of the so-called "constraint effect" (attributed as the influences of geometry size, loading level and even material mismatch) may cause significant influence on the creep crack growth and the integrity assessment of a structure at elevated temperature $[1,2]$. As the influence of so-called "constraint effect" [3-5], the understanding of the dominance of $C(t)$ in creeping solids is concerned by both researchers and engineers in recent years [6-10].

In fact, mixed mode crack problem is an important topic in fracture mechanics and the mixed creep crack is commonly found in actual engineering structures [11-14]. With the foundation work of Shih [15], the mixed mode crack under small scale yielding condition was analyzed, and detailed dimensionless angular stress functions under different plastic mixity factors have been tabled by Symington and coworkers [16]. Aoki et al. [17] presented a study on the crack tip deformation for mixed mode crack tip field of elastoplastic material, and they found that there exists both sharpening and blunting effect under the large deformation of mixed type crack. Later, Du et al. [18] discussed the $J$-dominance for mixed type crack and found that the application of $J$ - $T$ two parameter theory under mixed mode is not as good as pure mode I case. Roy and Narasimhan [19] made a thorough investigation on the $J$-dominance of mixed type elastoplastic material, and the dominance of $J$ decreases as the mixity approaches to 1 according to their study. The experimental work given by Roy and Narasimhan [20] also showed that the influence of constraint effect on fracture toughness of aluminum alloy for mixed mode crack.

To characterize the constraint effect of the mixed type crack, some researchers proposed different constraint parameters for mixed I/II crack in plastic materials, e.g. Sutton et al. [21] defined the stress triaxiality as the constraint parameter. Ayatollahi et al. [22] proposed a $Q_{\text {II }}$-parameter in the maximum tangential stress direction in a mode II boundary layer model, and their solutions is quite similar to the $Q$ parameter given by O'Dowd and Shih [23]. Subramanya et al. [24] proposed a numerical study of three dimensional mixed mode cracked boundary layer formulation considering the influence of out-of-plane constraint effect. Yang et al. [25] presented a high order term solutions

\footnotetext{
* Corresponding author.

E-mail addresses: ywdai@bjut.edu.cn (Y. Dai), yhliu@mail.tsinghua.edu.cn (Y. Liu), qfei@bjut.edu.cn (F. Qin), qianguian@imech.ac.cn (G. Qian), chao@sc.edu (Y.J. Chao).
} 


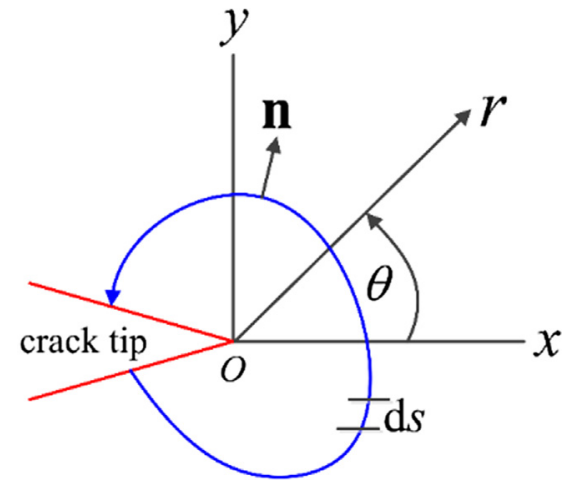

Fig. 1. Coordinate system used in the analysis.

Table 1

Loading conditions used in calculations.

\begin{tabular}{lll}
\hline$K_{\mathrm{I}}$ & $K_{\text {II }}$ & $M^{\mathrm{e}}$ \\
\hline 150 & 0 & 1.0 \\
150 & 75 & 0.7 \\
150 & 150 & 0.5 \\
75 & 150 & 0.3 \\
0 & 150 & 0.0 \\
\hline
\end{tabular}

for both mode I and mode II cases, and they found that the mode II case contains the smaller constraint effect than that of mode I. Tvergaard [26] also found that the fracture toughness for mode II case is higher than that of mode I case. There are also some other researchers who have concerned the constraint effect for mixed type crack, e.g. Roy and Narasimhan [20] presented the constraint effect for a hole ahead of blunted crack. Though there are many works [26-30] related with the elastic and plastic mixed type crack have been presented, discussions on the dominance of $C(t)$-integral for mixed type creep crack have not been reported yet in the available literatures.

For creep crack, Brockenbrough et al. [31] presented the transient creep crack tip field of mixed type, and they found that the deformation mode for mode I and mode II are different, and the growth rate for creep zone for mode II is several times larger than that of mode I. Busso et al. [32] presented a singular analysis for mixed type creep crack. Gordon and McDowell [33] used the triaxiality criterion to predict the crack initiation angle of bimaterial interface creep crack for Arcan-like specimen. It should be mentioned that the aforementioned results were
Table 2

Material properties used in calculations.

\begin{tabular}{lllll}
\hline $\begin{array}{l}\text { Young's } \\
\text { modulus }\end{array}$ & $\begin{array}{l}\text { Yielding } \\
\text { stress }\end{array}$ & Poisson's ratio & Creep coefficient & $\begin{array}{l}\text { Creep } \\
\text { exponent }\end{array}$ \\
\hline $125 \mathrm{GPa}$ & $180 \mathrm{MPa}$ & 0.3 & $2.64 \times 10^{-16}$ & 5 \\
\hline
\end{tabular}

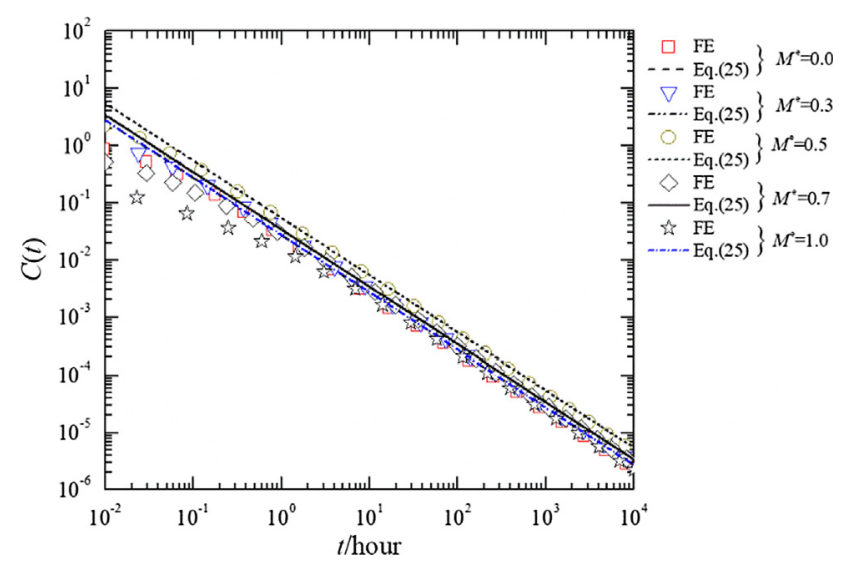

Fig. 3. Comparisons of $C(t)$-integral under different remote elastic mixity factors with Eq. (25) and FE solutions.

based on crack tip field analysis.

In recent advances, though some works [6-12] have been made to characterize the constraint effect for pure mode I or pure mode II creep crack with different considerations, however, there is no literature available to discuss the dominance of $C(t)$ in mixed mode I/II type creep crack tip field as far as the authors' knowledge. According to the recent investigation reported by Dai et al. [34,35], the constraint level can be influenced by $T$-stress under transient creep within small scale creep for mode I creep crack, however, the $T$-stress effect as well as the loss of dominance $C(t)$ have not been studied yet under mixed I/II condition.

The aim of the whole paper is to investigate the dominance of $C(t)$ integral for mixed I/II creep crack. Towards this aim, the transient creep for mixed type creep crack tip is studied in the Part I of the paper, and the investigations of mixed mode type creep crack under extensive creep will be presented in the Part II of the paper. The organization of the Part I of this paper is as follows. Framework of mixed mode creep crack tip fields for mixed mode I/II creep crack is presented in Section

(b)

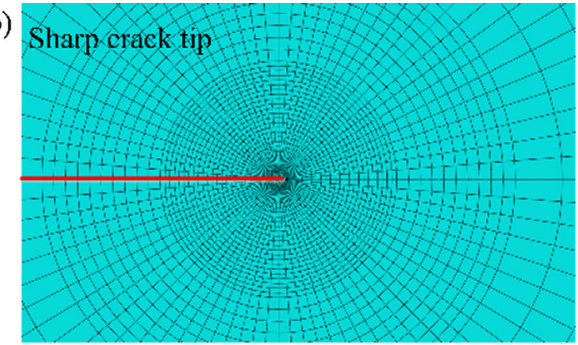

(c)

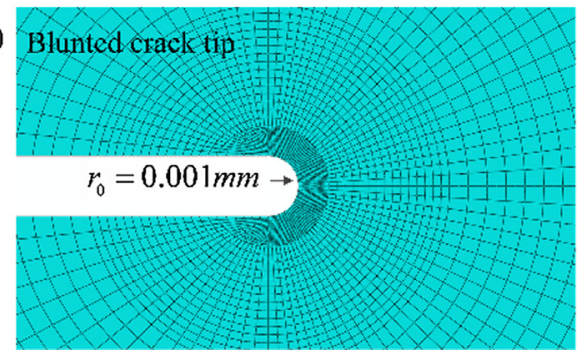

Fig. 2. FE meshes for (a) boundary layer model, (b) sharp crack tip and (c) blunted crack tip. 

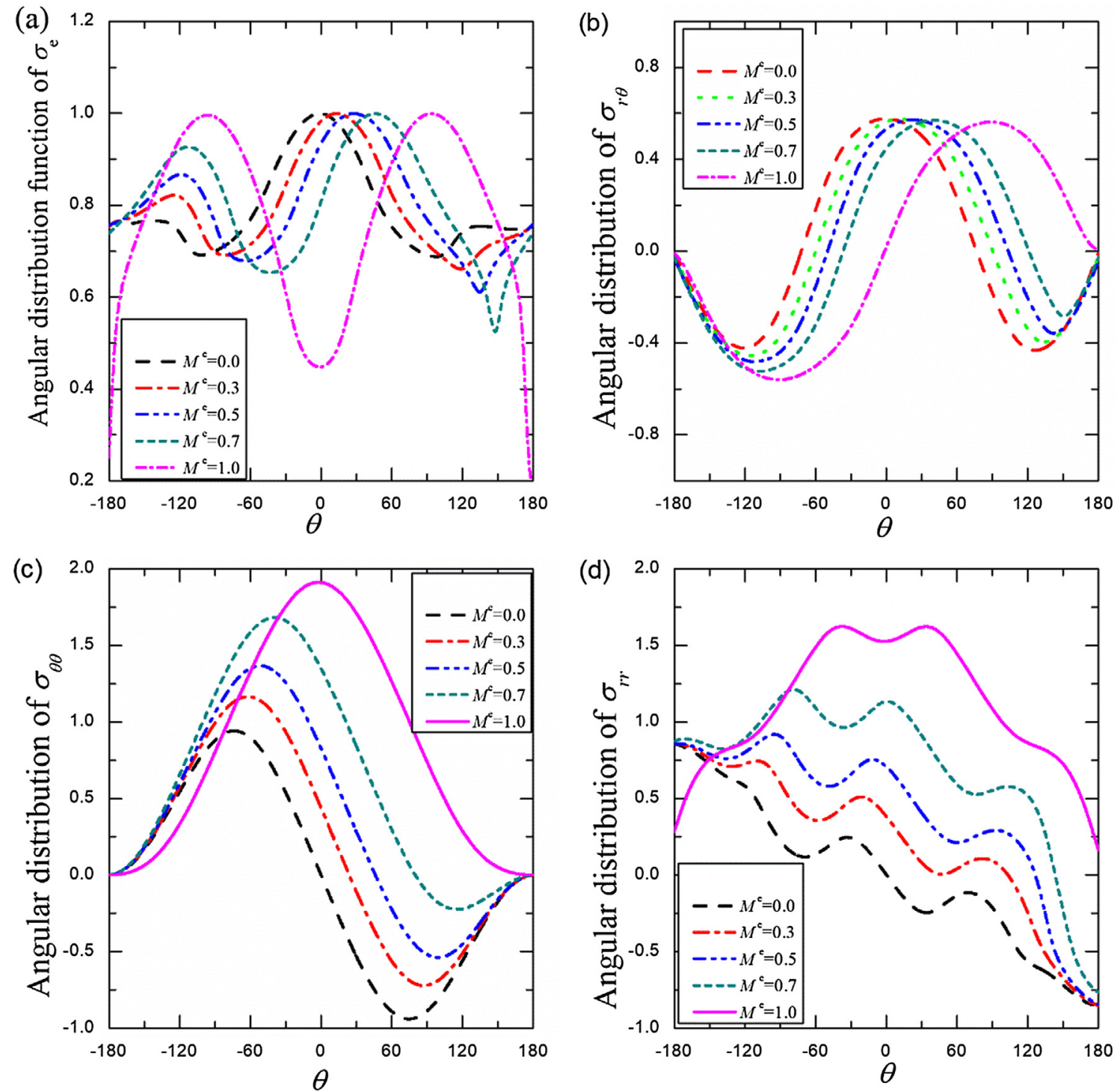

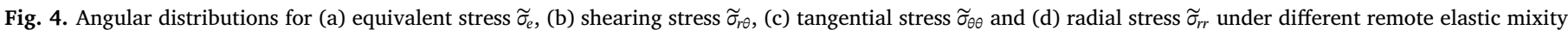
factors.

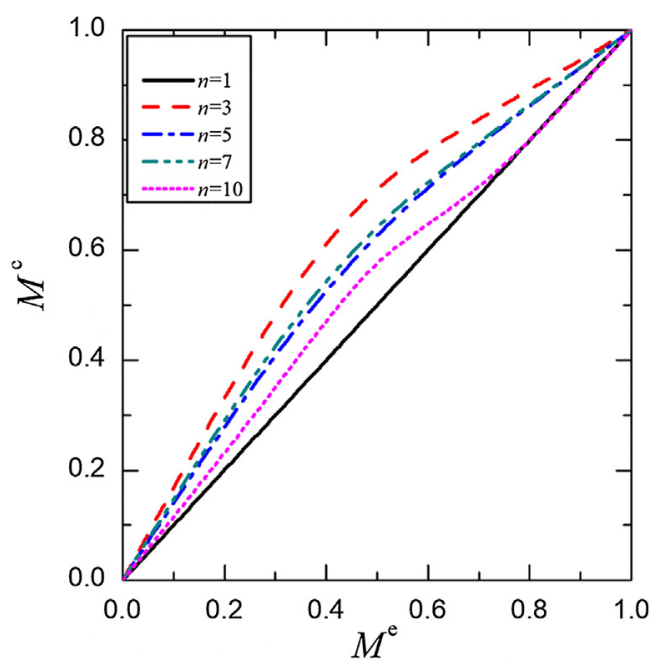

Fig. 5. Relations between remote elastic mixity factor and creep mixity factor.
Table 3

Comparisons of elastic, plastic and creep mixity factors.

\begin{tabular}{llllll}
\hline$M^{\mathrm{e}}$ & 0.0 & 0.3 & 0.5 & 0.7 & 1.0 \\
$M \mathrm{p}$ & 0.00000 & 0.4232 & 0.6348 & 0.7958 & 1.0 \\
$M^{\mathrm{c}}\left(t_{0.5}\right)$ & 0.00459 & 0.339 & 0.500 & 0.747 & 0.992 \\
$M^{\mathrm{c}}\left(10 t_{0.5}\right)$ & 0.00432 & 0.402 & 0.634 & 0.789 & 0.990 \\
$M^{\mathrm{c}}(10,000$ hr. $)$ & 0.00278 & 0.423 & 0.638 & 0.797 & 0.992 \\
\hline
\end{tabular}

2. The finite element model and numerical procedures are given in Section 3. The results and analyses are given in Section 4. The discussions is presented in Section 5. The concluding remarks are drawn in the last section.

\section{Framework of mixed I/II creep crack tip field}

\subsection{Constitutive equation}

For the multiaxial state, the strain rate-stress relation of power-law creep is written as [36] 

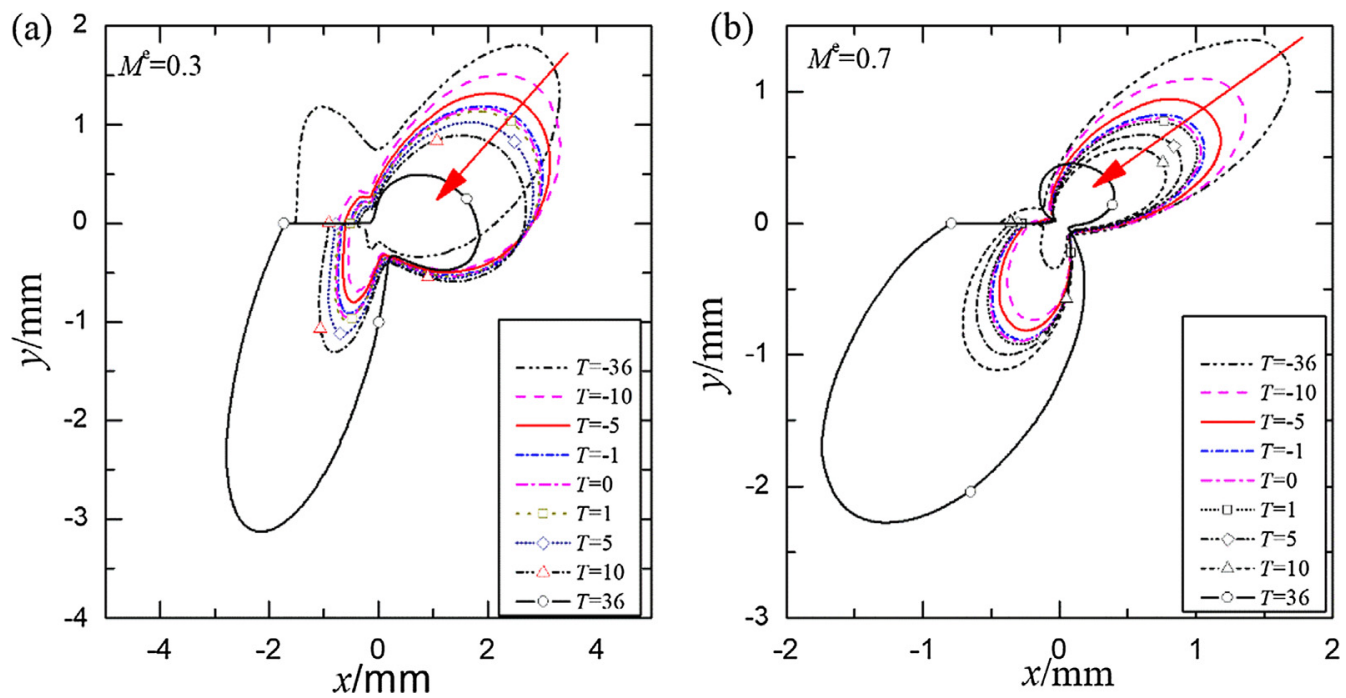

Fig. 6. Equivalent creep zone under different $T$-stress levels for (a) $M^{\mathrm{e}}=0.3$ and (b) $M^{\mathrm{e}}=0.7$.

Table 4

Variations of creep zone area under different $T$-stress levels.

\begin{tabular}{|c|c|c|c|c|c|c|c|c|c|c|}
\hline & $T=$ & -36 & -10 & -5 & -1 & 0 & 1 & 5 & 10 & 36 \\
\hline$M^{\mathrm{e}}=0.3$ & & 9.678 & 5.831 & 5.172 & 4.847 & 4.794 & 4.714 & 4.594 & 4.527 & 7.495 \\
\hline$M^{\mathrm{e}}=0.7$ & & 2.507 & 1.865 & 1.521 & 1.382 & 1.351 & 1.333 & 1.278 & 1.311 & 4.461 \\
\hline
\end{tabular}

$\dot{\varepsilon}_{i j}=\frac{1+v}{E} \dot{S}_{i j}+\frac{1-2 v}{3 E} \dot{\sigma}_{k k} \delta_{i j}+\frac{3}{2} \dot{\varepsilon}_{0}\left(\frac{\sigma_{e}}{\sigma_{0}}\right)^{n-1} \frac{S_{i j}}{\sigma_{0}}$

$S_{i j}=\sigma_{i j}-\sigma_{k k} \delta_{i j} / 3$

$\sigma_{e}^{2}=\frac{3}{2} S_{i j} S_{i j}$

where $E, v, n$ and $\delta_{i j}$ are the elastic modulus, Poisson's ratio, creep exponent and Kronecker delta, respectively. As the question discussed in this paper is for two-dimensional plane strain condition, the subscript $i$, $j$ take $r, \theta$ respectively. The polar coordinate for the crack tip used in the following content is shown in Fig. 1. The creep constant is defined as $B=\dot{\varepsilon}_{0} / \sigma_{0}^{n}$.

\subsection{Asymptotic crack tip field for mixed mode creep crack}

In this analysis, small strain is assumed and the stress-strain fields are treated to be separable in $r$ and $\theta$. The stress components of a powerlaw creeping material with two terms expansion in the asymptotic form are given as [7]:

$\frac{\sigma_{i j}(r, \theta, t)}{\sigma_{0}}=A_{1}(t) \bar{r}^{s_{1}} \tilde{\sigma}_{i j}^{(1)}(\theta)+$ higher order terms

where

$\left\{\begin{array}{c}\bar{r}=r / L \\ s_{1}=-1 /(n+1) \\ A_{1}(t)=\left(\frac{C(t)}{\sigma_{0} \varepsilon_{0} I_{n} L}\right)^{-s_{1}}\end{array}\right.$

in which $C(t), s_{i}, I_{n}$ and $L$ are the $C(t)$-integral, stress exponent, integral constant and characteristic length of the crack tip field, respectively. $\tilde{\sigma}_{i j}^{(1)}(\theta)$ are the angular functions of stress distributions of the first order.

$C(t)$ is defined as [37]

$C(t)=\int_{\Gamma \rightarrow 0} W^{*} \mathrm{~d} y-T_{i}\left(\frac{\partial \dot{u}_{i}}{\partial x}\right) \mathrm{d} s$

in which, as shown in Fig. 1, $\Gamma$ is a counterclockwise integration contour around the crack tip, and $T_{i}, \dot{u}_{i}, \mathrm{~d} y$ and $\mathrm{d} s$ are the traction vector on $\Gamma$, the displacement rate, the increments in $y$-direction and along $\Gamma$, respectively. Under steady state creep or extensive creep, $C(t)$ can be replaced by a path-independent integral $C^{*}$. For the first order term, the stress exponent $s_{1}$ is equal to $-1 /(n+1)$ for both mixed I/II mode cracks.

The asymptotic expansion for the rate of strains can be presented as [7]:

$\frac{\dot{\varepsilon}_{i j}(r, \theta, t)}{\dot{\varepsilon}_{0}}=A_{1} \bar{r}^{s_{1}} \tilde{\eta}_{i j}^{(1)}(\theta)+B A_{1}^{n} \bar{r}^{n s} \tilde{\varepsilon}_{i j}^{(1)}(\theta)+$ higher order terms

in which

$\left\{\begin{array}{c}B=\frac{\dot{\varepsilon}_{0}}{\sigma_{0}^{n}} \\ \widetilde{\varepsilon}_{i j}^{(1)}=\frac{3}{2}\left[\widetilde{\sigma}_{e}^{(11)}\right]^{n-1} \widetilde{S}_{i j}^{(1)} \\ \widetilde{\eta}_{i j}^{(1)}=\frac{1+v}{E \dot{\varepsilon}_{0}} \dot{\widetilde{S}}_{i j}^{(1)}+\frac{1-2 v}{3 E \dot{\varepsilon}_{0}} \dot{\widetilde{\sigma}}_{k k}^{(1)} \delta_{i j}\end{array}\right.$

With the strain rate relation Eq. (7), the dimensionless displacement rate can be written as:

$\frac{\dot{u}_{i}(r, \theta, t)}{\dot{\varepsilon}_{0} L}=A_{1}^{n} \bar{r}^{n s_{1}+1} \tilde{u}_{i}^{(1)}(\theta)+$ higher order terms

in which

$\left\{\begin{array}{c}\widetilde{u}_{r}^{(1)}=\frac{\widetilde{\varepsilon}_{r r}^{(1)}}{n s_{1}+1} \\ \widetilde{u}_{\theta}^{(1)}=\frac{2 \widetilde{\varepsilon}_{r \theta}^{(1)}-\widetilde{u}_{r, \theta}^{(1)}}{n s_{1}}\end{array}\right.$

Substituting the basic governing Eq. (4), Eq. (7) and Eq. (9) into equilibrium equation, strain rate and displacement rate relation, the following ordinary differential equation systems with first order term can be obtained: 

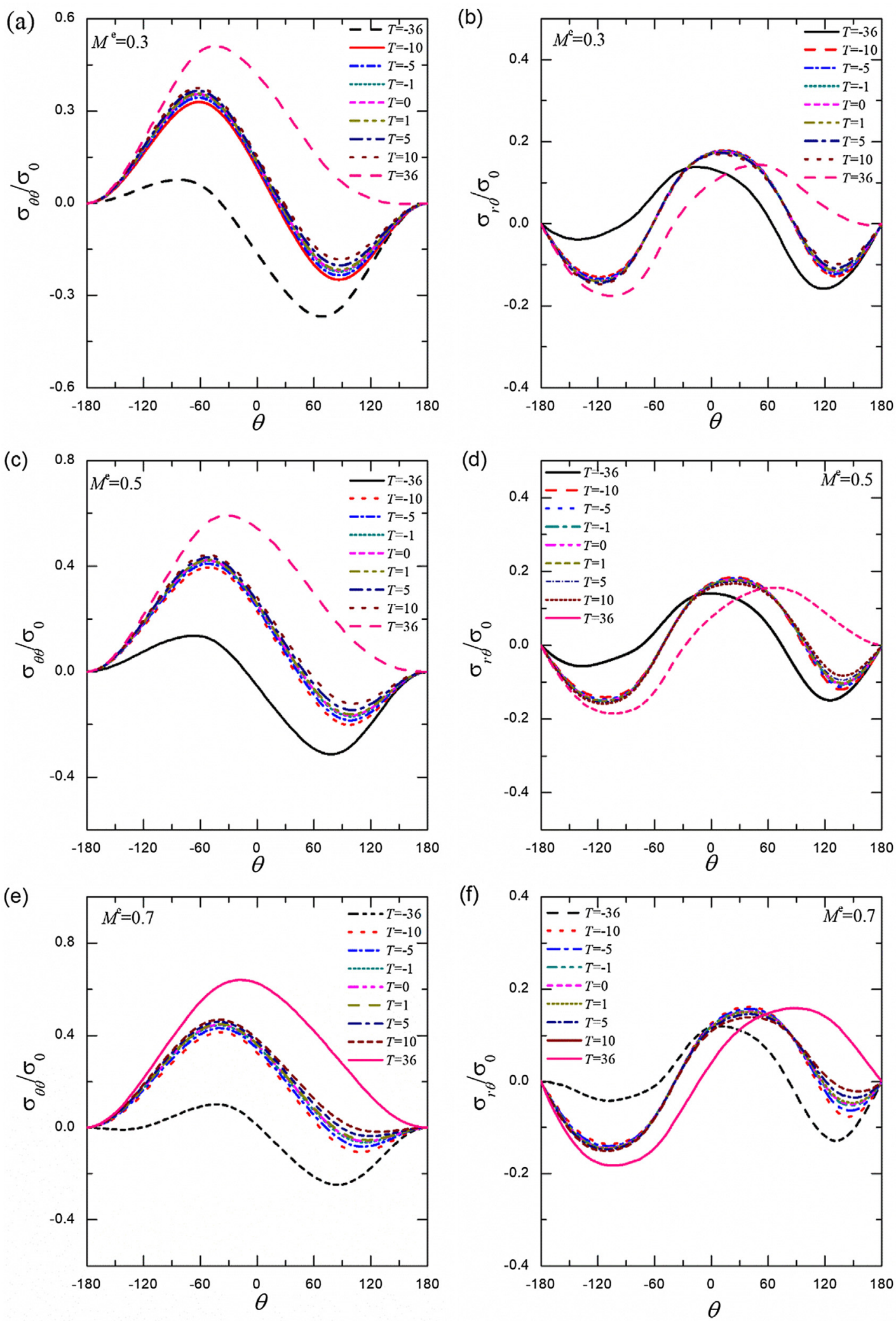

Fig. 7. Angular distributions for dimensionless tangential stress and shearing stress component under various $T$-stress level with different elastic mixity factors. 

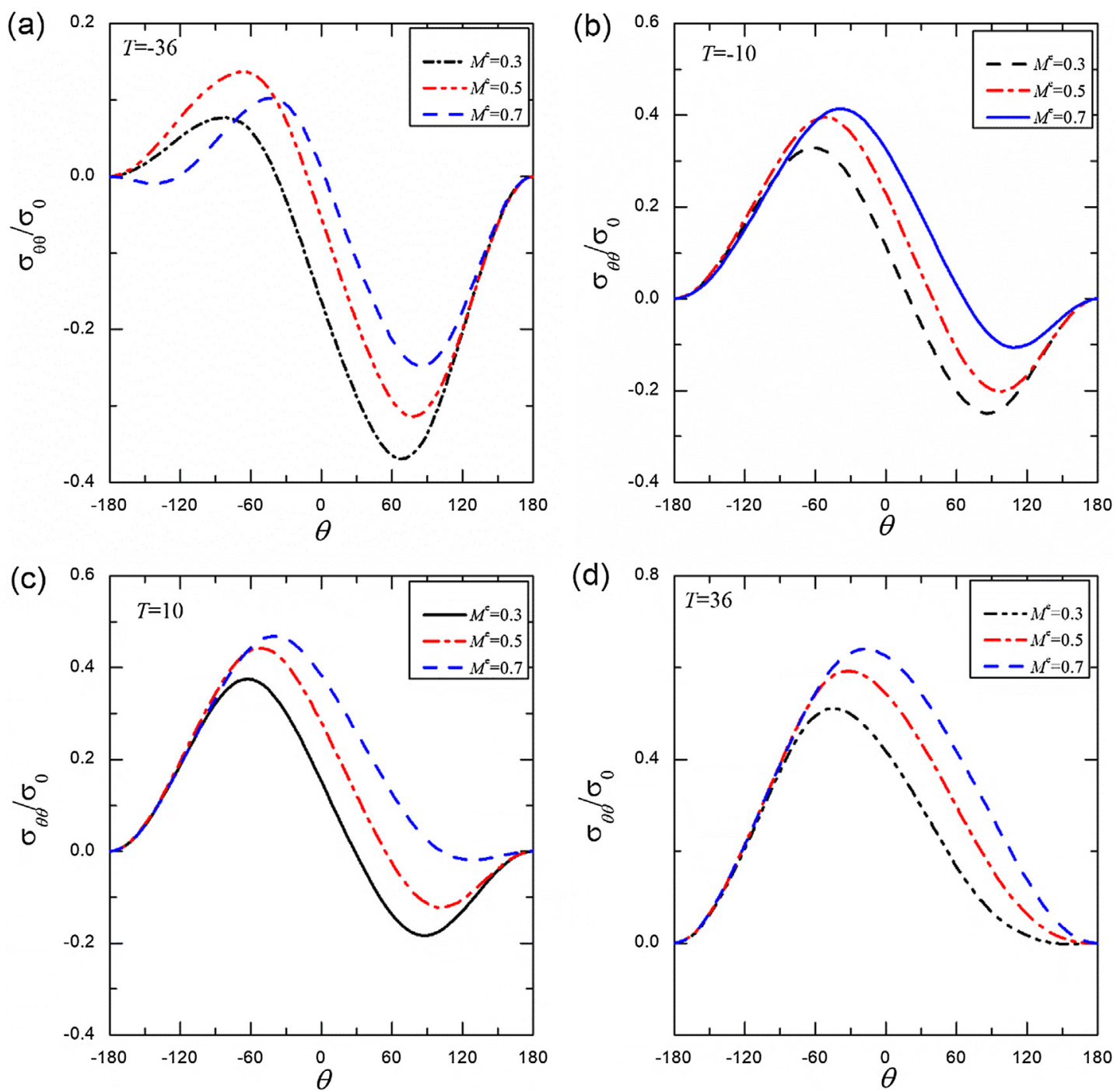

Fig. 8. Angular distribution for dimensionless tangential stress and shearing stress component under various $T$-stress level with different elastic mixity factors.

$$
\left\{\begin{array}{c}
\left(s_{1}+1\right) \widetilde{\sigma}_{r r}^{(1)}-\widetilde{\sigma}_{\theta \theta}^{(1)}+\widetilde{\sigma}_{r \theta, \theta}^{(1)}=0 \\
\widetilde{\sigma}_{\theta \theta, \theta}^{(1)}+\left(S_{1}+2\right) \widetilde{\sigma}_{r \theta}^{(1)}=0 \\
\widetilde{\varepsilon}_{r r}^{(1)}-\left(n s_{1}+1\right) \widetilde{u}_{r}^{(1)}=0 \\
\widetilde{\varepsilon}_{\theta \theta}^{(1)}-\widetilde{u}_{r}^{(1)}-\widetilde{u}_{\theta, \theta}^{(1)}=0 \\
2 \widetilde{\varepsilon}_{r \theta}^{(1)}-\widetilde{u}_{r, \theta}^{(1)}-n s_{1} \widetilde{u}_{\theta}^{(1)}=0
\end{array}\right.
$$

In order to solve Eq. (11), creep mixity factor is defined as a supplement boundary condition which is given as below:

$\tilde{M}^{\mathrm{c}}=\frac{2}{\pi}\left|\arctan \left(\frac{\tilde{\sigma}_{\theta \theta}^{(1)}(\theta=0)}{\tilde{\sigma}_{r \theta}^{(1)}(\theta=0)}\right)\right|$

where $\widetilde{\sigma}_{\theta \theta}^{(1)}$ and $\widetilde{\sigma}_{r \theta}^{(1)}$ are the angular distribution function of tangential stress and shearing stress of the first order solutions, respectively. The solution of Eq. (11) has been recently solved by Dai [38] and demonstrated that the solutions coincide with the solutions presented by Shih [15] and solutions recently revisited by Shlyannikov and Tumanov [29] very well.

\subsection{Maximum tangential stress criterion in mixed mode creep crack}

The maximum tangential stress (MTS) criterion was commonly adopted for both homogeneous linear material and elastoplastic material to predict the crack initiation direction of mixed mode [39]. Herein, the MTS direction for mixed mode creep crack field can be calculated as follows [39]:

$\frac{\partial \sigma_{\theta \theta}}{\partial \theta}=0, \frac{\partial^{2} \sigma_{\theta \theta}}{\partial \theta^{2}}<0$

Considering Eq. (13), the above formula can be rewritten as:

$\frac{\partial \widetilde{\sigma}_{\theta \theta}}{\partial \theta}=0, \frac{\partial^{2} \widetilde{\sigma}_{\theta \theta}}{\partial \theta^{2}}<0$

in which $\widetilde{\sigma}_{\theta \theta}$ is the dimensionless angular distribution of tangential stress of the first order. The angle which satisfies Eq. (14) is denoted as $\theta_{\text {MTS. }}$

\subsection{Constraint characterization parameter}

According to the asymptotic crack tip field analysis in Section 2, the higher order term may be used to characterize the constraint effect of the mixed mode creep crack. Herein, the following constraint parameters for mixed I/II creep crack tip field are selected as the higher order terms given in Eq. (4) which are presented as below [22]:

$Q^{\prime}=\frac{\sigma_{\theta \theta}-\sigma_{\theta \theta}^{\mathrm{ref}}}{\sigma_{0}}$ at $\theta=0$ 

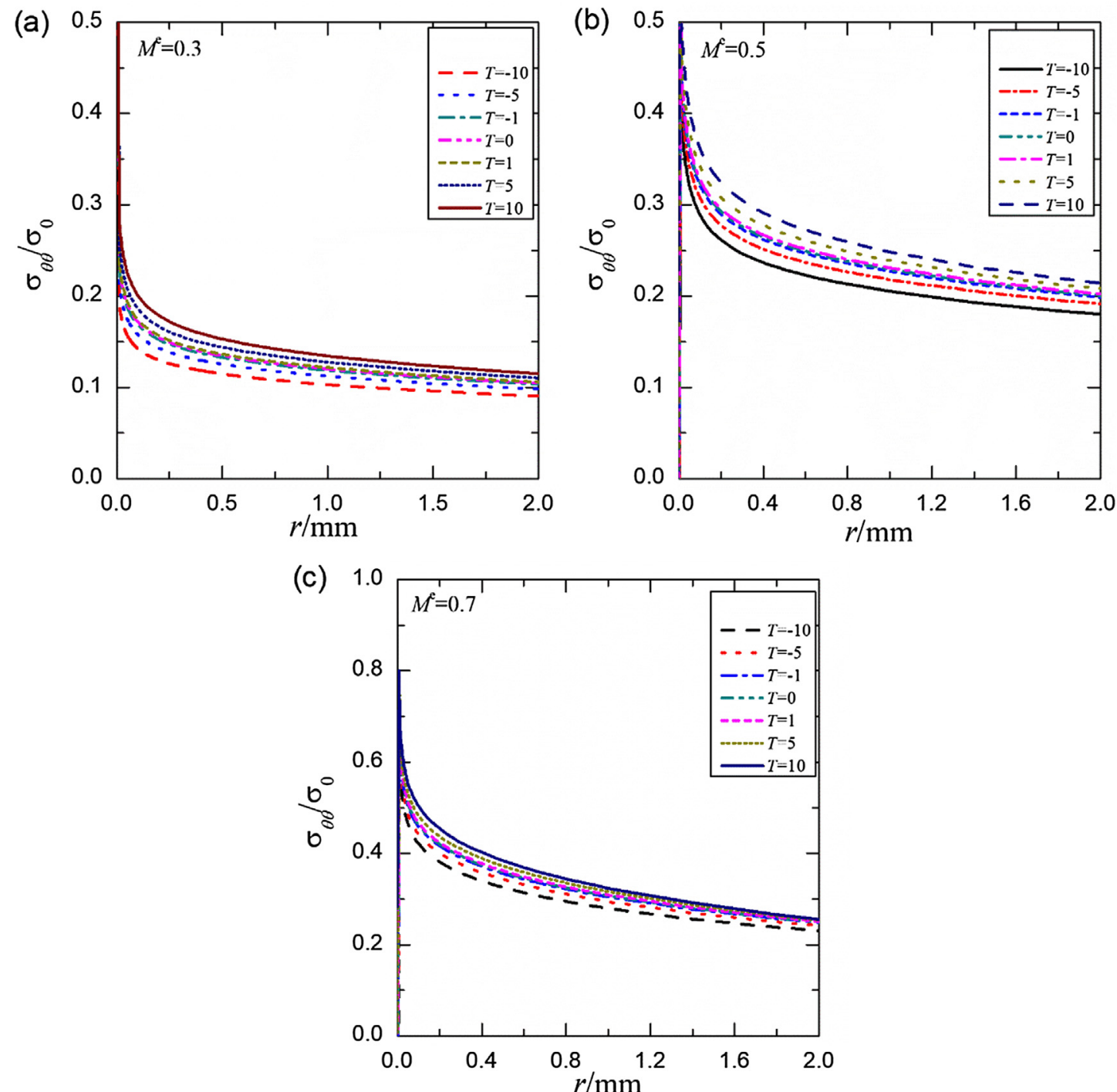

Fig. 9. Radial distribution for dimensionless opening stress under various $T$-stress level for remote elastic mixity factor (a) 0.3 , (b) 0.5 and (c) 1.0 .

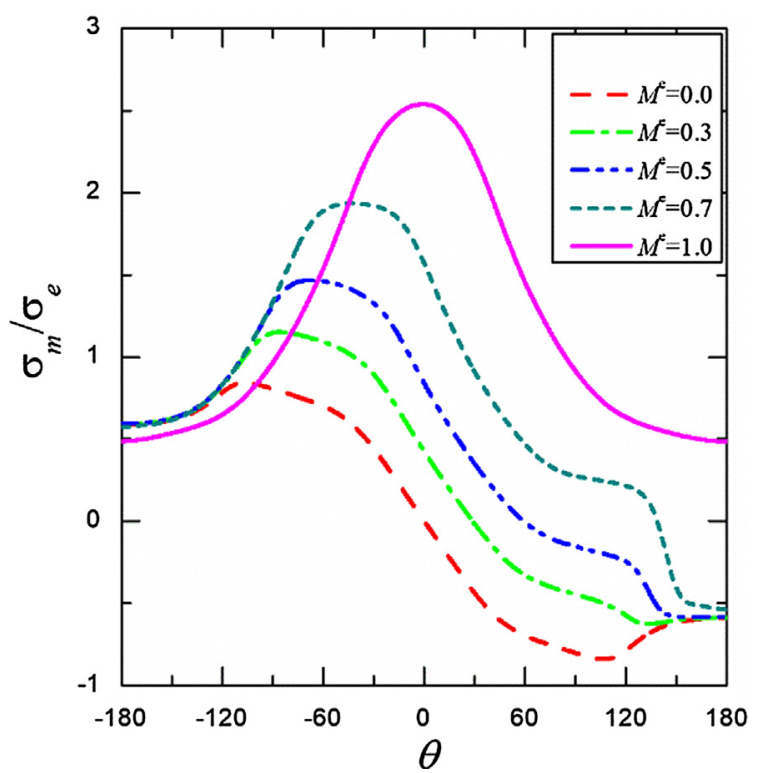

Fig. 10. Variations of stress triaxiality under different remote elastic mixity factors.
$Q^{*}=\frac{\sigma_{\theta \theta}-\sigma_{\theta \theta}^{\text {ref }}\left(\theta_{\mathrm{MTS}}\right)}{\sigma_{0}}$ at $\theta=\theta_{\mathrm{MTS}}$

where $\sigma_{\theta \theta}^{\text {ref }}$ is the tangential stress calculated with the selected reference stress field, and $\sigma_{\theta \theta}^{\text {ref }}\left(\theta_{\text {MTS }}\right)$ is also the obtained tangential stress of HRR field under the theoretical analysis along MTS direction. The difference between these two equations mentioned above are also needed to be compared so as to confirm the application of these two equations. For creep crack tip field, the maximum tangential stress direction is determined by Eq. (14).

Herein, the $\sigma_{\theta \theta}^{\text {ref }}$ can be also represented by the opening stress of $T$ stress with zero if it is under small scale creep. Hence, $Q^{\prime}$ and $Q^{*}$ is defined as below under small scale creep condition according to the previous investigations given by Dai $[33,34]$ and by Zhao et al. [40].

$Q^{\prime}=\frac{\sigma_{\theta \theta}-\sigma_{\theta \theta}^{\mathrm{ref}, T=0}}{\sigma_{0}}$ at $\theta=0$
$Q^{*}=\frac{\sigma_{\theta \theta}-\sigma_{\theta \theta}^{\mathrm{ref}, T}=0}{\sigma_{0}}\left(\theta_{\mathrm{MTS}}\right)$
at $\theta=\theta_{\mathrm{MTS}}$

\section{Numerical procedures}

In order to achieve transient creep, the boundary layer model with 

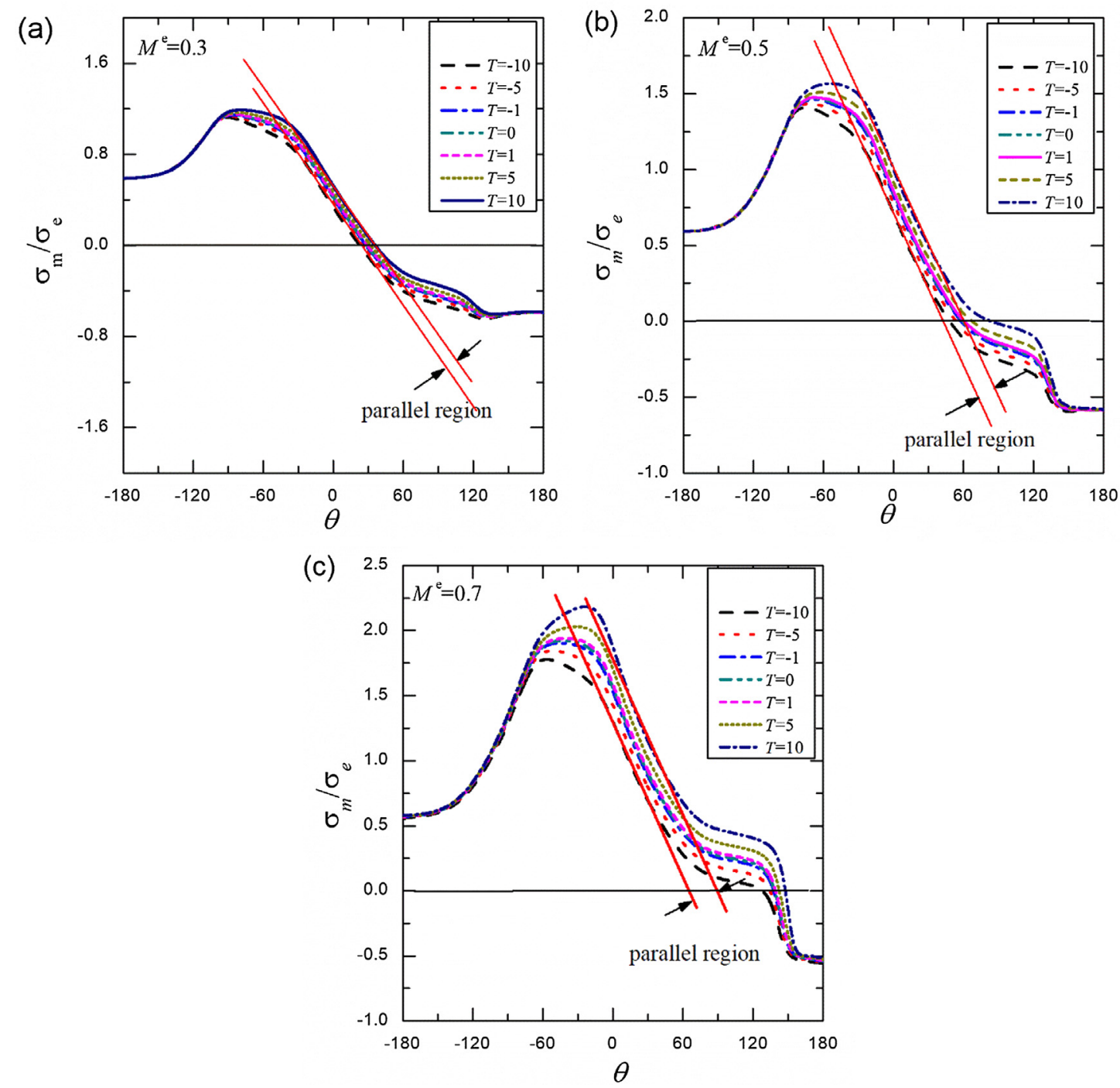

Fig. 11. Variations of stress triaxiality under different $T$-stress level in angular direction.

mixed type crack is adopted $[34,41]$. The detail specimen configurations, boundary conditions and material properties are given in Section 3.1. Modelling verifications are presented in Section 3.2.

\subsection{Specimen configurations, boundary conditions and material properties}

The boundary layer model was widely used to characterize the constraint effect of small scale yielding problem. This model is recently developed to analyse the effect of constraint effect for small scale creep for mode I creep crack $[6,35]$ and this model is only applicable under transient creep. The boundary layer model is always a circle plate in which the crack is placed in radius direction with an enforced boundary condition. The applied outer boundary conditions is written as below [18]:

$$
\begin{gathered}
\left.\left.u_{x}=\sqrt{\frac{r}{2 \pi} \frac{(1+v)}{E}\left[K_{\mathrm{I}} \cos \frac{\theta}{2}(k-\right.}+1+2 \sin ^{2} \frac{\theta}{2}\right)+K_{\mathrm{II}} \sin \frac{\theta}{2}\left(k+1+2 \cos ^{2} \frac{\theta}{2}\right)\right] \\
+T \frac{1-v^{2}}{E} r \cos \theta
\end{gathered}
$$

$$
\begin{gathered}
\left.\left.u_{y}=\sqrt{\frac{r}{2 \pi} \frac{(1+v)}{E}\left[K_{\mathrm{I}} \sin \frac{\theta}{2}(k\right.}+1-2 \cos ^{2} \frac{\theta}{2}\right)-K_{\mathrm{II}} \cos \frac{\theta}{2}\left(k-1-2 \sin ^{2} \frac{\theta}{2}\right)\right] \\
-T \frac{v(1+v)}{E} r \sin \theta
\end{gathered}
$$

where $u_{x}$ and $u_{y}$ are the displacements in $x$-direction and $y$-direction, respectively. $K_{\mathrm{I}}, K_{\mathrm{II}}, r, \theta, T$ and $E$ are stress intensity factor (SIF) of mode I, mode II, distance from crack tip, $T$-stress and Young's modulus, respectively. In Eqs. (15) and (16), $k=3-4 v$ for plane strain condition.

Herein, the radius of the boundary layer model is taken as $1000 \mathrm{~mm}$, with a reasonable loading level the results are ensured to be under small scale creep regime. Under boundary layer model, the applied load at the outer boundary of the model is list in Table 1 if it's not stated specially in this paper. The applied loading level is controlled with different remote elastic mixity factors so as to govern the mixity of the creep crack front, and the remote elatic mixity factor here is defined as:

$M^{\mathrm{e}}=\frac{2}{\pi} \arctan \left(\frac{K_{\mathrm{I}}}{K_{\mathrm{II}}}\right)$

in which $K_{\mathrm{I}}$ and $K_{\mathrm{II}}$ are mode I SIF and mode II SIF, respectively. In order to characterize the creep mixity factor under the numerical computations, a finite element based creep mixity factor is defined as below:

$M^{\mathrm{c}}=\frac{2}{\pi}\left|\arctan \left(\frac{\sigma_{\theta \theta}(\theta=0)}{\sigma_{r \theta}(\theta=0)}\right)\right|$

where $\sigma_{\theta \theta}$ and $\sigma_{r \theta}$ are the tangential stress and shear stress components, respectively. 

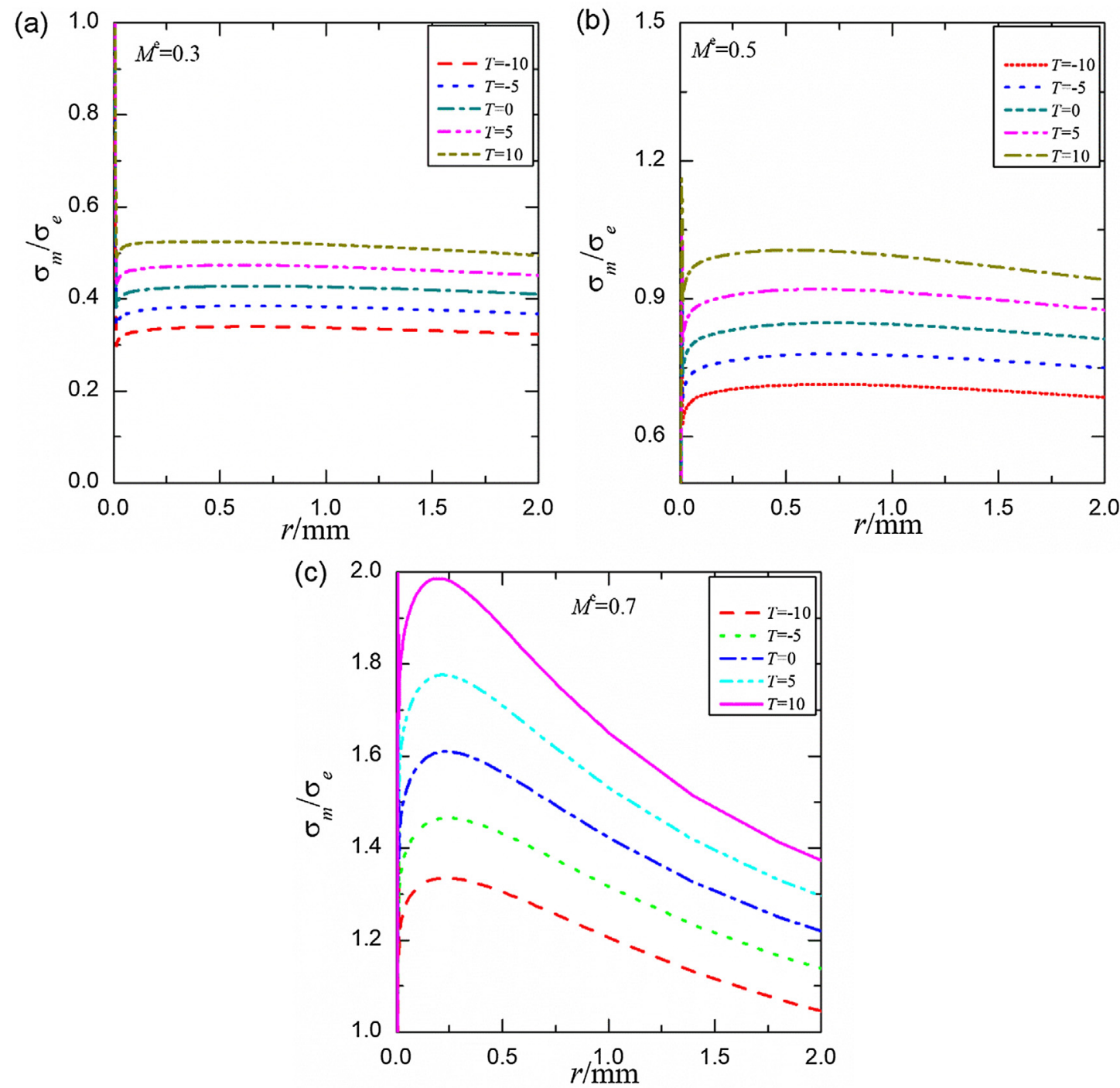

Fig. 12. Variations of stress triaxiality under different $T$-stress levels in radial direction.

The finite element (FE) models for boundary layer model is presented in Fig. 3. The element type used for boundary layer model is eight nodes plane strain element with reduced integration (CPE8R). Two crack tip models are adopted here in which one is the sharp crack tip (see Fig. 2(b)) and another is the blunted crack tip (see Fig. 2(c)). For sharp crack tip, the element type of the first ring is the singular element with single node collapsed element. There are around 8611 elements with 26,052 nodes in the entire modelling. For the blunted type crack tip mode, the notch radius for the blunted crack, $r_{0}$, takes $0.001 \mathrm{~mm}$.

Herein, the power-law creep constitutive equation presented in Eq. (1) is adopted here. The material properties used in calculations are shown in Table 2. The Young's modulus $E$, nominal yielding stress $\sigma_{0}$, Poisson's ratio $v$ are kept as $125 \mathrm{GPa}, 180 \mathrm{MPa}$ and 0.3 , respectively. The creep coefficients, i.e. denoted as $B$ in Eq. (1), are selected as $2.64 \times 10^{-16}$ corresponding with creep exponent $n=5$. The material properties selected here are backgrounded with P92 steel [40].

\subsection{FE verification}

To validate the mesh quality and accuracy of the modelling, FE calculations are performed before the analysis of the investigation. For the boundary layer model, the stress intensity factor (SIF) and T-stress are verified here. The SIF is calculated with the contour integral method implemented by ABAQUS itself. As a verification of the result, the applied $K_{\mathrm{I}}, K_{\mathrm{II}}$ and $T$-stress at the outer boundary of the boundary layer are $75 \mathrm{MPa} \cdot \mathrm{mm}^{1 / 2}, 75 \mathrm{MPa} \cdot \mathrm{mm}^{1 / 2}$ and $-10 \mathrm{MPa}$, respectively. SIF and Tstress of the near field extracted from FE code ABAQUS are $75.35 \mathrm{MPa} \cdot \mathrm{mm}^{1 / 2}, 73.98 \mathrm{MPa} \cdot \mathrm{mm}^{1 / 2}$ and $-10.04 \mathrm{MPa}$, respectively. It can be found that relative error between the applied $K_{\mathrm{I}}, K_{\mathrm{II}}$ and $T$-stress and the extracted solutions are $0.467 \%, 1.36 \%$ and $0.4 \%$, respectively. Hence, the mesh quality and FE accuracy presented in the analysis are fine enough.

\section{Results and analyses}

\subsection{Basic characteristics of mixed I/II creep crack tip fields under transient creep}

\subsection{1. $C(t)$-integral estimation of mixed I/II creep crack}

For mode I creep crack, a transition time to characterize the transition between transient creep and extensive creep which can be presented as below [42]:

$t_{\mathrm{T}}^{\mathrm{I}}=\frac{\left(1-v^{2}\right) K_{\mathrm{I}}^{2}}{(n+1) E C^{*}}$

The superscript of $t_{\mathrm{T}}^{\mathrm{I}}$ is denoted as the mode I case. The $C(t)$-integral under mode I condition can be estimated as follows: 

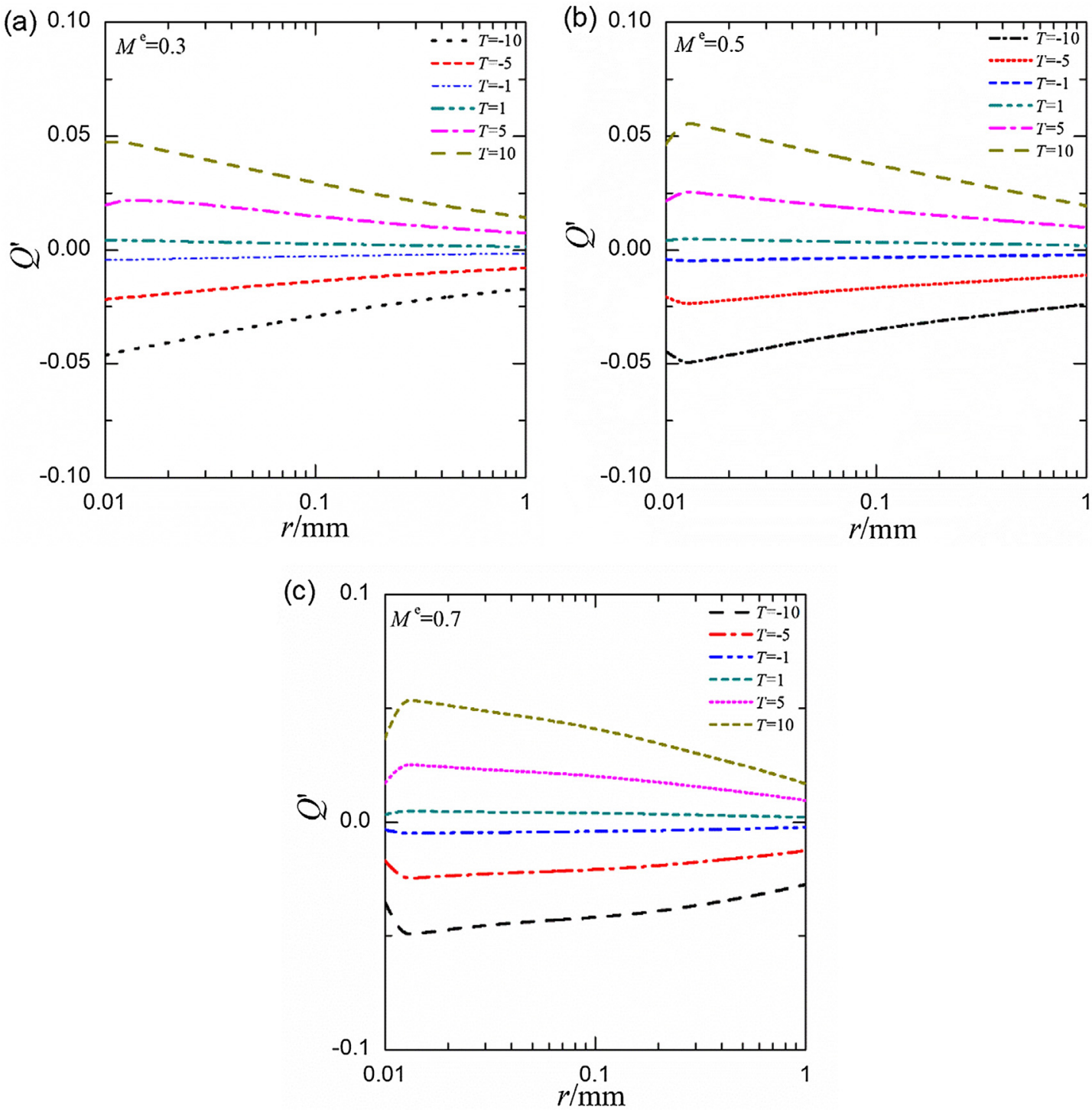

Fig. 13. Variations of $Q^{\prime}$ with radial distance under various $T$-stresses.

$C(t)=\frac{\left(1-v^{2}\right) K_{I}^{2}}{(n+1) E t}$

where $t$ is the creep time.

Similar to the derivation of Eq. (24), the following formula is proposed to calculate $C(t)$-integral for creep crack under mixed mode condition as below and the detail derivation is presented in Appendix A.

$C(t)=\frac{\left(1-v^{2}\right)\left(K_{\mathrm{I}}^{2}+K_{\mathrm{II}}^{2}\right)}{(n+1) E t}$

in which $K_{\mathrm{I}}$ and $K_{\mathrm{II}}$ are the mode I stress intensity factor and mode II stress intensity factor for the same cracked specimen, respectively. The limit condition for application of Eq. (24) is that the creep regime is transient which represents that the creep condition is under transient creep.

In order to verify Eq. (25), comparisons of the solutions calculated with Eq. (25) and numerical results extracted from FE code ABAQUS are presented in Fig. 3 where $C(t)$-integral are calculated under different remote elastic mixity factors. Herein, the results extracted from FE code ABAQUS are computed by averaging ten integration contours ahead of crack tip. From Fig. 3, it can be seen that the solutions presented by Eq. (25) coincide quite reasonably with the solutions computed with FE. It indicates that $C(t)$-integral can be estimated with the proposed Eq. (25).

\subsubsection{Angular stress distribution function}

With the characteristics of creep crack front for mixed mode creep crack tip field presented in Section 2, the distributions of dimensionless stress component under various remote elastic mixity factors are given in Fig. 4. It should be pointed out that remote elastic mixity factor $M^{\mathrm{e}}$ is determined by the applied SIF at the outer boundary. It is considered to be the pure mode II case for $M^{\mathrm{e}}=0.0$ and pure mode I case for $M^{\mathrm{e}}=1.0$. It is considered to be mixed type if $0.0<M^{\mathrm{e}}<1.0$. The corresponding loading conditions is presented in Table 1 . The solutions are obtained at a creep time of $10,000 \mathrm{~h}$.

Herein, the angles of maximum angular tangential stress under various mixity factors are $-72^{\circ},-58.5^{\circ},-49.5^{\circ},-36^{\circ}$ and $0^{\circ}$, respectively. Except the MTS direction, the maximum value of the angular tangential stress also increases with the rise of elastic mixity factor. The maximum value of normalized radial stress is also found to be influenced by the elastic mixity factor of the far field under the boundary layer model and the radial stress heightens with the increase of the remote elastic mixity factor.

4.1.3. Relations between creep mixity factor and elastic mixity factor Due to the important role of the applied outer boundary loading of 

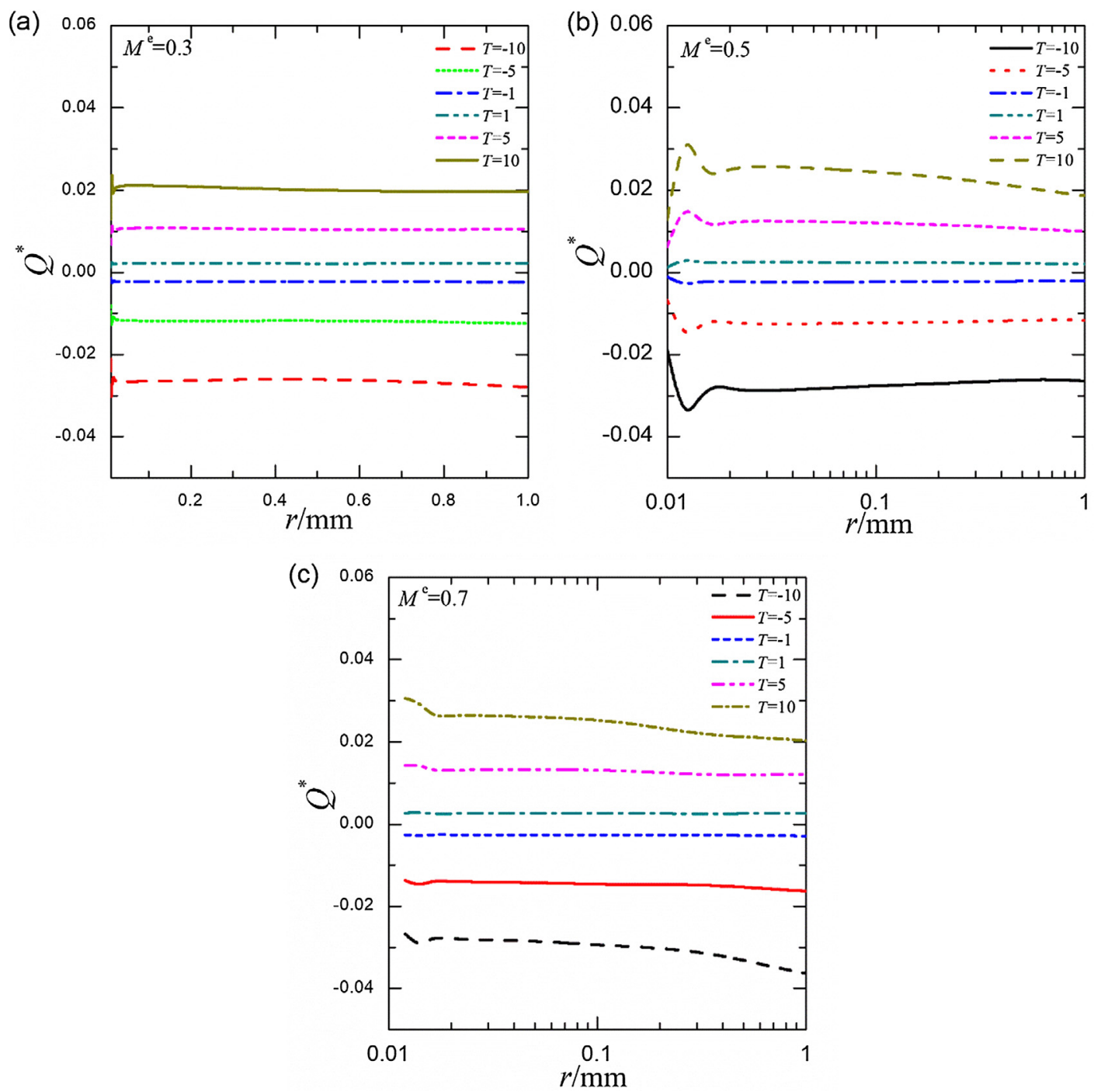

Fig. 14. Variations of $Q^{*}$ along radial distance under various $T$-stresses.

Table 5

Applied loading and effective SIF.

\begin{tabular}{llll}
\hline$M^{\mathrm{e}}$ & $K_{\mathrm{I}}$ & $K_{\mathrm{II}}$ & Effective SIF \\
\hline 0.0 & 0.0 & 212.13 & 212.13 \\
0.3 & 94.868 & 189.736 & 212.13 \\
0.5 & 150 & 150 & 212.13 \\
0.7 & 189.736 & 94.868 & 212.13 \\
1.0 & 212.13 & 0.0 & 212.13 \\
\hline
\end{tabular}

the boundary layer model, herein, the relation between elastic mixity factor and creep mixity factor is presented in Fig. 5 which could take the influence of creep exponent into consideration. It can be found that the creep mixity factor is higher than that of elastic mixity factor and presents a nonlinear relations. The relations presented here are not only dependent on creep exponent, but also dependent on creep coefficient.

As the difficulty of obtaining the extensive creep for boundary layer model, the transition time is hardly be reached. Herein, a parameter $t_{0.5}$ is defined here which represents that the creep time when equivalent creep strain level of 0.001 reaches to $0.5 \mathrm{~mm}$ away from crack tip. The $t_{0.5}$ for different elastic mixity factors are respectively 10000, 490, 25.52, 42.34 and $43.55 \mathrm{~h}$ corresponding to elastic mixity factors varying from 1.0 to 0.0 .

With the given normalized stress method, the creep mixity factor can be obtained at any creep time. Herein, the creep mixity factors at creep time of $t_{0.5}, 10 t_{0.5}$ and $10,000 \mathrm{~h}$ are presented in Table 3 , and the comparisons between plastic mixity factors and creep mixity factors are also made in Table 3. The plastic mixity factors are obtained from Shih [15] with his proposed relationship between elastic mixity factor and plastic mixity factor. It can be found that the creep mixity factors under various far field at creep time of $10 t_{0.5}$ and $10,000 \mathrm{~h}$ are almost equal to the plastic mixity factors which quite coincide well with our numerical analyses. For creep time of $t_{0.5}$, the creep mixity factors present some slight difference compared with creep mixity factor of longer creep time. The reason is that some region of the creep crack tip field is still under control of elastic field so that elastic mixity factor approaches to the creep mixity factor gradually with accumulation of creep strain.

\subsection{Influence of T-stress}

The creep zone can reflect the dominance of $C(t)$ to some extent, the influence of $T$-stress level on the equivalent creep strain area of the mixed type creep crack is presented in Fig. 6. The results here are obtained under the same remote elastic mixity factor, i.e. the same effective SIF. The specific value of equivalent creep zone area surrounded around the mixed creep crack tip is list in Table 4. It can be seen clearly that the equivalent creep strain area is strongly influenced by the applied remote $T$-stress level. Compared with the area of the equivalent 

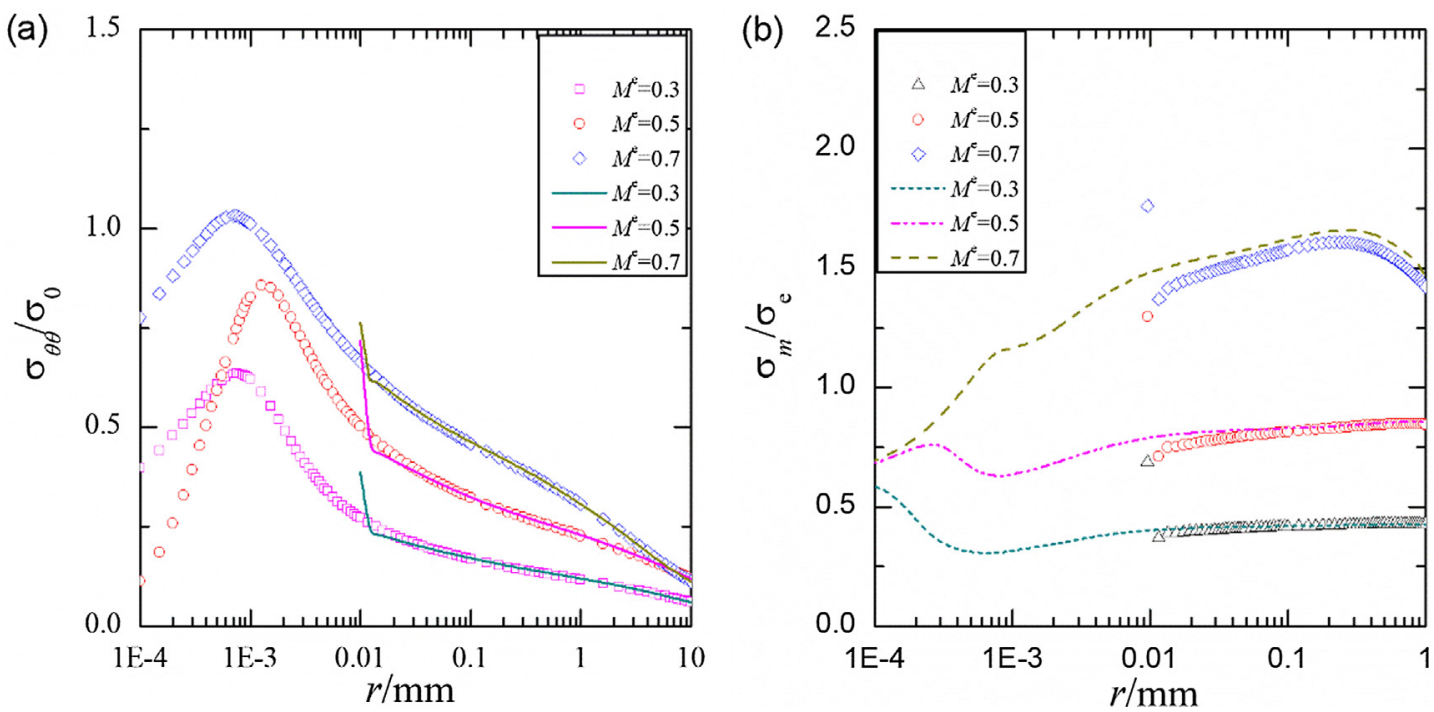

Fig. 15. Comparisons of opening stress and triaxiality for mixed mode crack tip field along crack line.

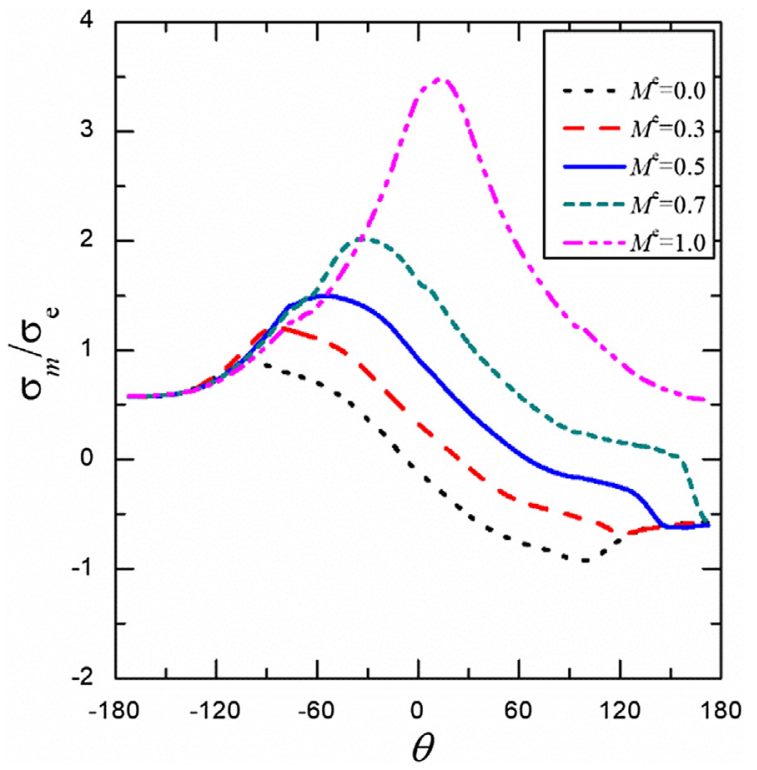

Fig. 16. Stress triaxiality under various mixity factors for blunted crack tip.

creep strain region under $T=0$, the equivalent creep strain region under non-zero $T$-stresses are always the higher than that of $T=0$. Compared with the lower remote elastic mixity factor, the crack tip field of higher remote elastic mixity factor has the lower creep region. For $\left|T / \sigma_{0}\right|<0.1$, the influence of $T$-stress on the area of the creep zone is not as significant as the elastic mixity factor, e.g. the region under $M^{e}=0.3$ at $T=-10$ is more than three times of $M^{e}=0.7$. Hence, the mixity factors plays significant role on determining of the loss of constraint effect.

\subsubsection{Angular distributions of stress components}

Angular distributions for tangential stress and shearing stress under different $T$-stress level for mixed type creep crack tip are presented in Fig. 7. These results are obtained at a fixed distance $0.5 \mathrm{~mm}$ from crack tip. Only mixed factors with $0.3,0.5$ and 0.7 (shown in Fig. 7) are presented here to study the influence of $T$-stress level on the near creep crack tip field. The applied $T$-stress level varies from $-36,-10,-5,-1$, $0,1,5,10$ and 36 . We considered that the $T$-stress value here are classified to be two levels: the $\left|T / \sigma_{0}\right|<0.1$ including $-10,-5,-1,0,1$, 5,10 and the $\left|T / \sigma_{0}\right|>0.1$ with \pm 36 . For $\left|T / \sigma_{0}\right|<0.1$, the creep crack tip field is considered to be transient creep as the creep region here is much smaller than that of elastic region.

However, the tangential stress or so-called opening stress increase greatly under the positive $T$-stress and decrease significantly for negative $T$-stress if $\left|T / \sigma_{0}\right|>0.1$ according to the numerical results presented here. This phenomenon here is quite different from that of elastoplastic solutions given by Ref. [43] which presents the positive opening stress even for negative $T$-stress level. It should be mentioned that the $T$-stress defined in the elastic far field may vary with the increase of the creep time, however, it can be treated as a constant if the creep strain is so much less than the elastic strain at the far field under the transient creep.

Comprehensively considering the influence of $T$-stress on opening stress, it can be found that the opening stress under different remote elastic mixity factors are influenced by the $T$-stress level though they are under the same external loading. The opening stress increase with the enhancement of positive $T$-stress even for mixed type creep crack tip field, and also decrease with the reduce of the negative $T$-stress. The larger decrease of the $T$-stress level, the opening stress drops more significantly. This conclusion here is also suitable for $M^{\mathrm{e}}=0.5$ and 0.7 . However, it should be pointed out that the difference of opening stress between the zero $T$-stress and non-zero $T$-stress enlarges with the increase of remote elastic mixity factors. It implies the influence of $T$ stress on the creep crack tip field heightens as the crack tip field approaches to be the standard mode I type creep crack. For the shearing stress of far field $M^{\mathrm{e}}=0.3$, the influence of $T$-stress on the shearing stress component is not that significant except for the locations for the minimum value if $\left|T / \sigma_{0}\right|<0.1$. The shearing component varies greatly if $\left|T / \sigma_{0}\right|>0.1$.

To make a comparison of the variations of dimensionless opening stress under a specific $T$-stress level, Fig. 8 is presented to state the influence of the remote elastic mixity factor. It can be seen that the minimum value of opening stress decreases with the rise of elastic mixity factors for $T / \sigma_{0}=-0.2$. The minimum value of opening stress shown here under negative $T$-stress is compressive stress. However, the opening stress increases with the enhancement of the elastic mixity factor for $T / \sigma_{0}=-0.2$. The opening stress is strongly based on the applied elastic mixity factors of far field for BLF model. It's sure that the opening stress approaches to be the mode I case as the increase of the far field elastic mixity factor. The variation tendencies are quite similar with $T= \pm 10$ for the small level of $T$-stress, e.g. $T= \pm 1$ and \pm 5 . 

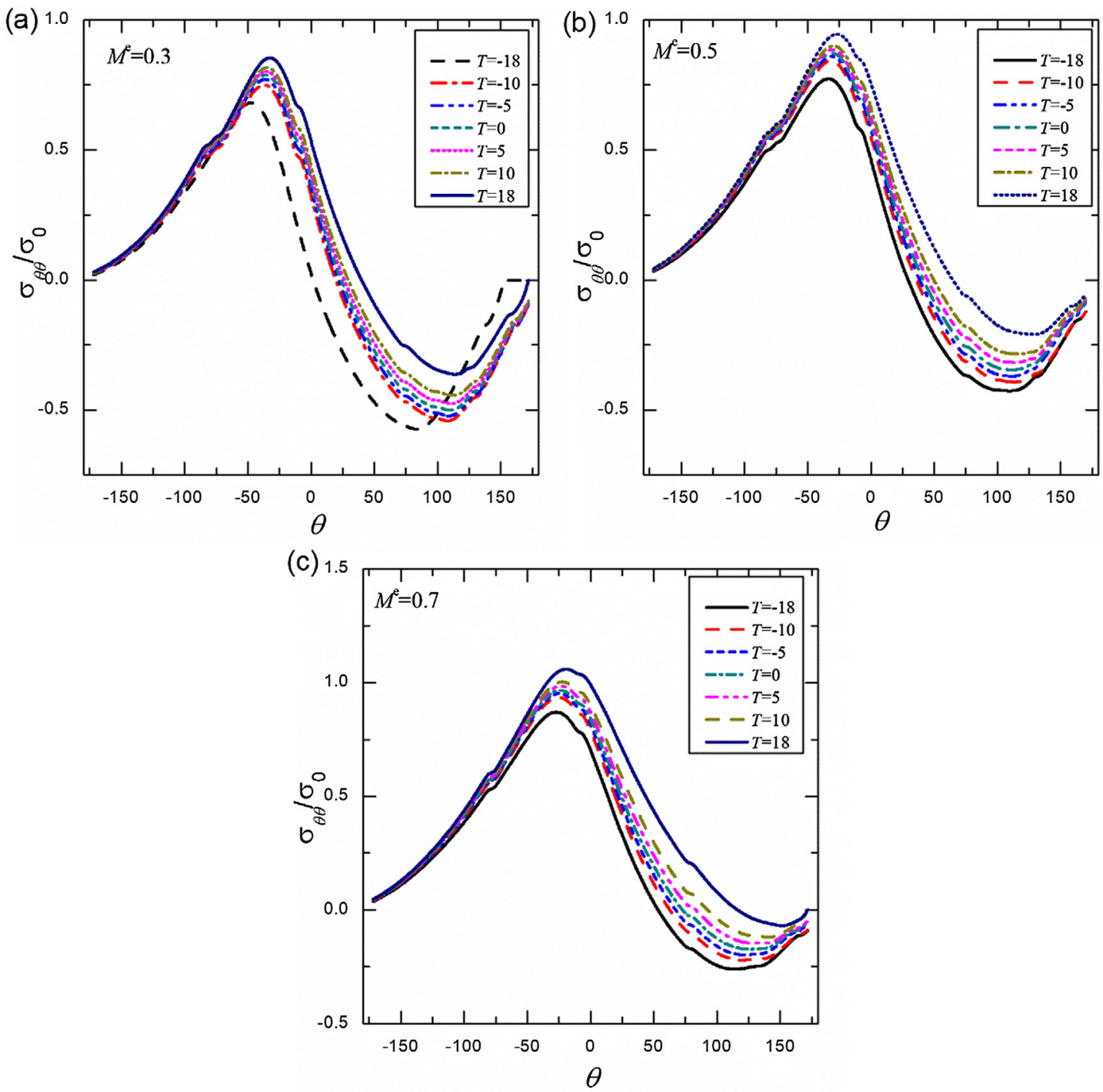

Fig. 17. Influence of $T$-stress on opening stress of blunted crack tip under various mixity factors along angular direction.

\subsubsection{Radial distributions of opening stress}

Except for the angular distribution function, the stress field characterization in the radial direction is also needed. According to the investigations presented by Wang et al. [10], the opening stress within distance away from crack tip are selected as $0-2 \mathrm{~mm}$ which includes the fracture process zone. Herein, results of three elastic mixity factors are presented here (shown in Fig. 9). The opening stress here are obtained at $\theta=0^{\circ}$ with three different elastic mixity factors, e.g. $0.3,0.5$ and 0.7 . As the boundary layer model presents that the small scale creep at $10,000 \mathrm{~h}$, there is no much difference at different creep time except for a slight relaxation. It can be seen that the opening stress are significantly influenced by the $T$-stress level of far field for different elastic mixity factors.

Clearly, the $T$-stress level also influence the constraint level of mixed mode creep crack tip field. It can be seen that the deviation from the HRR field, i.e. the $T$-stress equals to zero condition, increase as the rise of $T$-stress level. For positive $T$-stress, the opening stress is larger than that of $T=0$. The loss dominance $\mathrm{C}(t)$ is significant for negative $T$ stress. Similarly, the opening stress is smaller than that of $T=0$ for negative $\mathrm{T}$-stress conditions. It reveals that the positive $T$-stress obtains the higher constraint level and the negative $T$-stress can get the lower constraint level under small scale creep. This conclusion presented here is quite similar to that of elastoplastic condition under small scale yielding.

\subsubsection{Stress triaxiality}

Stress triaxiality, which is defined as the ratio of hydrostatic stress $\sigma_{m}$ and Mises equivalent stress $\sigma_{e}$, is also considered to be a parameter which is related with the constraint level. Stress triaxiality is also considered to be related with nucleation of voids and damage of microstructure. Herein, the variations of stress triaxiality in angular direction under different elastic mixity factors are presented in Fig. 10. The tendencies presented here shows the triaxiality mode for different mixed type of creep crack behaves quite differently. For $M^{\mathrm{e}}=0.0$, the stress triaxiality is antisymmetric along the crack front, and the stress triaxiality is symmetric about the crack front line for $M^{\mathrm{e}}=1.0$. The others conditions are among the pure mode I and mode II. It should be pointed out that there would be negative region for the mode II case and the compressive region will decrease as the increase of remote elastic mixity factor.

It means that the stress triaxiality relies on the mixity factors. To investigate the influence of $T$-stress on the stress triaxiality under different mixity factors, the stress triaxiality for different mixity factors are presented in Fig. 11. It can be found that stress triaxiality is also influenced by the $T$-stress level under various elastic mixity factors. For example of $M^{\mathrm{e}}=0.3$, the stress triaxiality changes with the variation of remote $T$-stress level between $-115^{\circ}$ to $120^{\circ}$. Except these regions, the stress triaxiality is almost not changed. Similar rule can be seen for $M^{\mathrm{e}}=0.5$ and 0.7 , however, the varied region is between about $-90^{\circ}$ to 

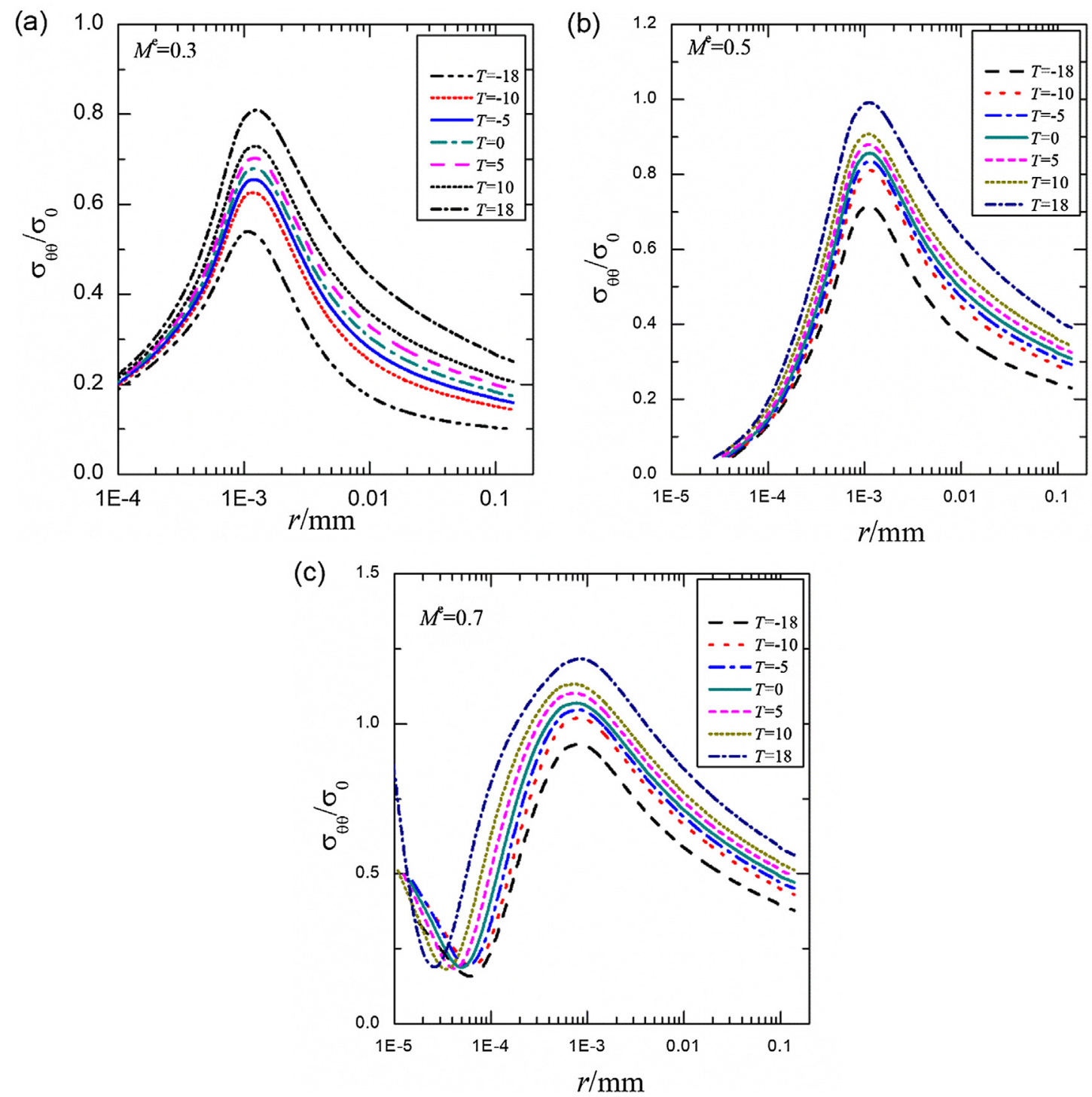

Fig. 18. Influence of $T$-stress on opening stress of blunted crack tip under various mixity factors in radial direction.

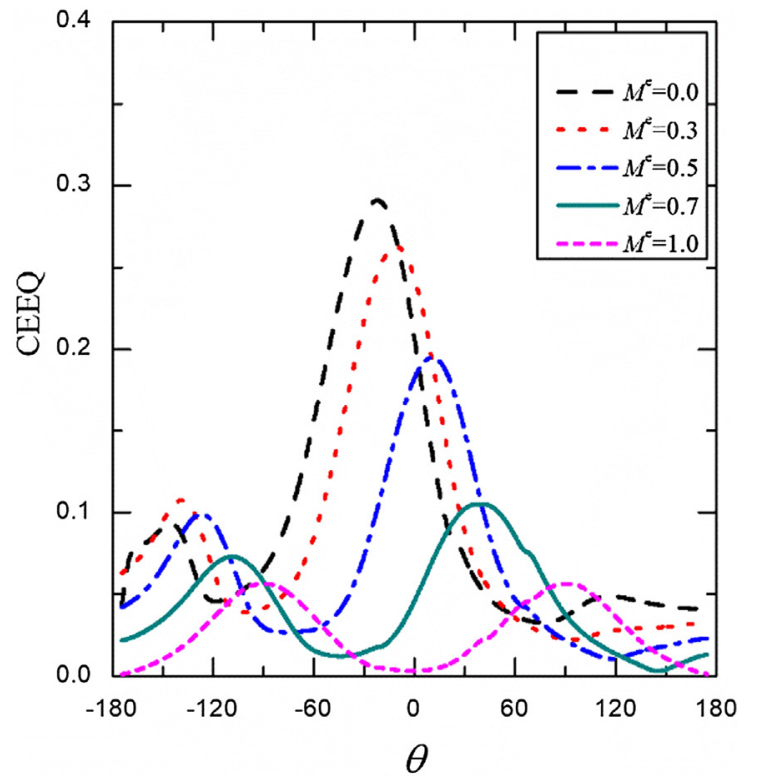

Fig. 19. CEEQ distribution under different mixity factors. $120^{\circ}$ and $-60^{\circ}$ to $130^{\circ}$. For the regions which are not located at these presented region mentioned above, the stress triaxiality is almost not affected by the remote $T$-stress. It can be also found that there exists a so-called parallel region for the stress triaxiality. Among these parallel regions, the stress triaxiality almost have the same slope, and the distance between these two paralleled lines enlarges with the increase of mixity factors. It reveals that the stress triaxiality plays more dominant role as the mixity factor approaches to pure mode I. It also demonstrates that the loss dominance $C(t)$ becomes more remarkable under the case where the mode I dominates most.

Except for the stress triaxiality in angular direction, the triaxiality along the crack line in radial direction under different $T$-stress for various remote elastic mixity factors are presented in Fig. 12. It can be seen that the stress triaxiality under mixed mode cases also heightens with the increase of $T$-stress level. However, the stress triaxiality is independent on distance from crack tip $r$ if remote elastic mixity factors approaches to mode II case, i.e. $M^{\mathrm{e}}=0.0$. However, the stress triaxiality is strongly dependent on radial distance.

\subsection{Constraint effect characterization of mixed I/II creep crack tip under} transient condition

The MTS direction $\theta^{*}$ under the remote elastic mixity factors with 

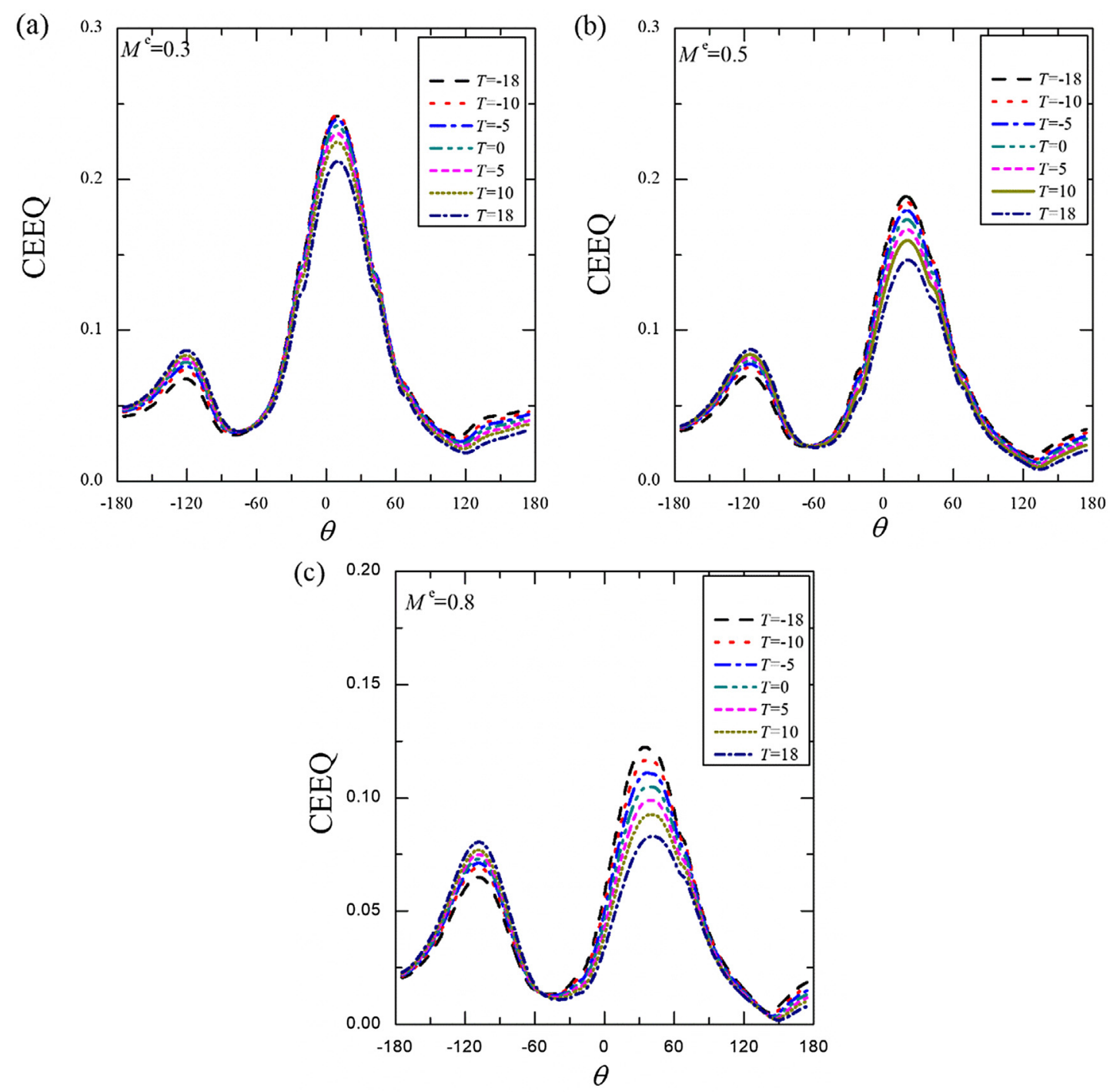

Fig. 20. Influence of $T$-stress on CEEQ of blunted crack tip under various mixity factors.

$M^{\mathrm{e}}=0.3,0.5$ and 0.7 are respectively $-63^{\circ},-49.5^{\circ}$ and $-40.5^{\circ}$. With the Eq. (17), the constraint effect parameter $Q^{\prime}$ are presented in Fig. 13. It can be seen that $Q^{\prime}$ is slightly increase with the rise of $T$-stress level. For the negative $T$-stress, this will lead to negative $Q^{\prime}$ and the positive $T$ stress level will lead to positive $Q^{\prime}$. For the same level of $T$-stress, the $Q^{\prime}$ slightly heightens with the increase of mixity factor. The $Q^{\prime}$ here decreases slightly with the distance away from the creep crack tip. These results here are obtained at a creep time of $10,000 \mathrm{~h}$.

$Q^{*}$ for various remote elastic mixity factors under different $T$-stress level are presented in Fig. 14. It can be found that $Q^{*}$ under positive $T$ stress slightly increase with the improvement of elastic mixity factor. $Q^{*}$ under positive $T$-stress is large than zero, while $Q^{*}$ under negative $T$ stress is smaller than zero. Compared with the value of $Q^{\prime}$ and $Q^{*}, Q^{*}$ has a smaller value than that of $Q^{\prime}$ though they are under the same loading level and same mixity factor. It can be seen that there is a platform which is almost not dependent on the distance away from crack tip within range of 0 to $1 \mathrm{~mm}$ which can include the fracture process zone. It is interesting as the constraint parameter presented in the direction of MTS presents to be independent of distance away from crack tip. However, $Q^{\prime}$ presented here is strongly dependent on distance away from crack tip. It should be noted that the value of $Q^{\prime}$ and $Q^{*}$ are not the same where maximum value of $Q^{\prime}$ is almost two times larger than that of $Q^{*}$. It may reveal that the two characterization mechanism here is totally different. Though the $Q^{*}$ under different remote elastic mixity factors.

\section{Discussions}

According to Aoki et al. [17], there exist both the blunting effect for mode I type crack and sharpening effect for mode II type crack of elastoplastic material. Under creep condition, the creep damage will play a much more significant role in the blunting effect of mode I cased creep crack tip field given by Wang et al. [10]. Hence, the finite strain deformation mode should be taken into consideration. In this section, the effective SIF for MBL formulation are kept as the same so that the $C(t)$-integral can be kept as the same in transient creep regime, and the detailed applied loading information is list in Table 5 .

\subsection{Influence of blunting effect}

Herein, a boundary layer model with a blunted crack tip is used and the loading conditions, geometry sizes and FE meshes has also been stated in Section 3. The detailed influence of the blunting effect on the creep crack tip field is needed here. The blunted crack tip radius is $1 \times 10^{-3} \mathrm{~mm}$ which is about $1 \times 10^{-6}$ times of the radius of the boundary layer model. Fig. 15 is presented to state the influence of blunting effect. It can be found that the difference region between the blunted one and sharp one with HRR singularity is about ten times of 

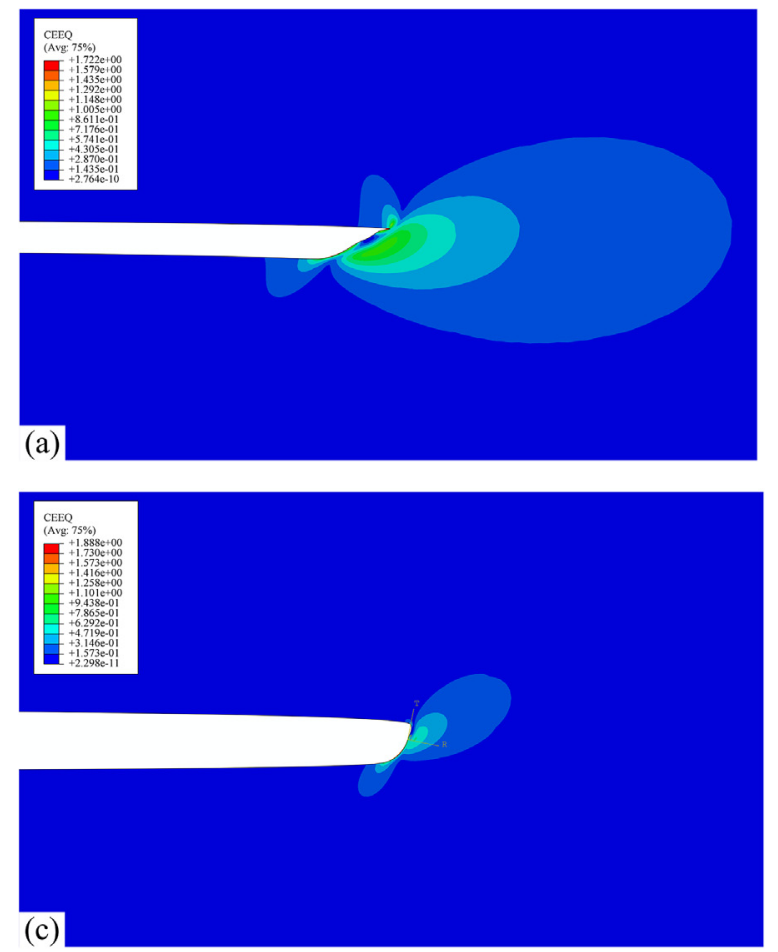

(b)
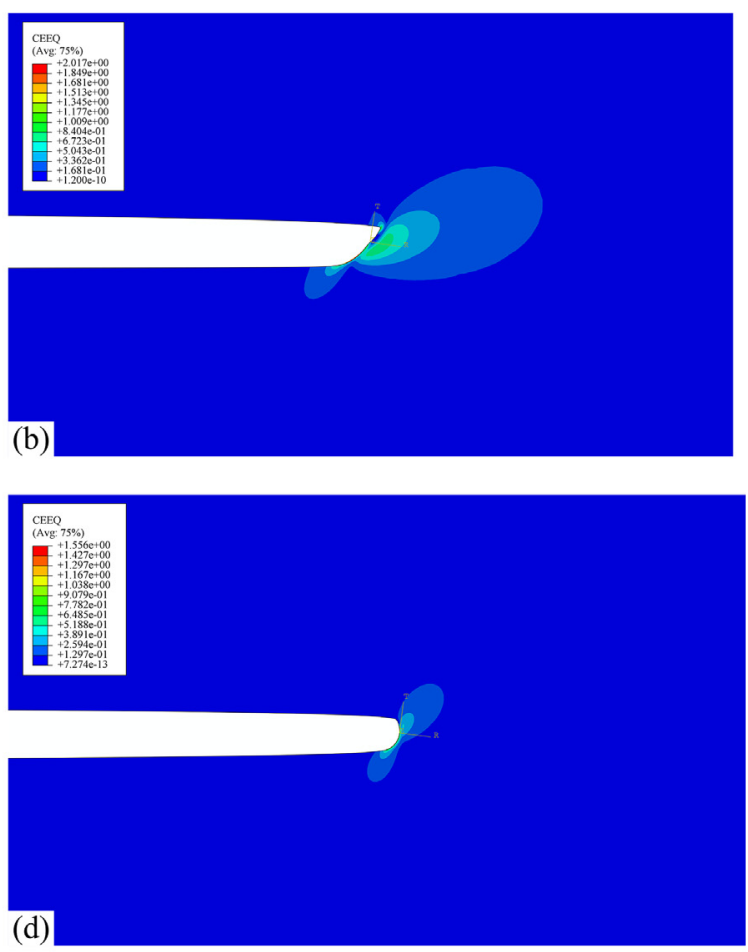

(d)

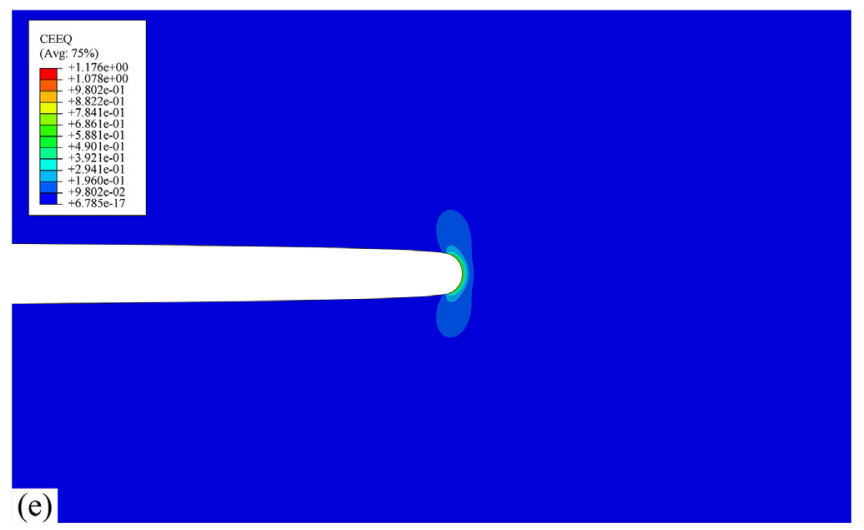

Fig. 21. Crack tip deformation under different remote elastic mixity factors, i.e. (a) 0.0, (b) 0.3 , (c) 0.5 , (d) 0.7 and (e) 1.0 .

radius of the blunted crack tip. The location where the maximum value of the opening stress appears is about the same length as the crack tip radius. For both opening stress and stress triaxiality for these presented conditions of mixed type crack, the influenced region is about ten times of the radius of blunted crack tip. The values of opening stress and stress triaxiality rise with the improvement of the mixity factor.

The stress triaxiality heightens as the mixity factor approaches to mode I case. It should be also noted that there exists the platform region which is independent of distance from the crack tip. However, the platform region diminishes as the crack type approaches to mode I case. The stress triaxiality for the blunted crack tip field is presented in Fig. 16 so as to investigate the stress triaxiality more clearly. It shows that the stress triaxiality presented here is quite similar to that of sharp crack with the remote elastic mixity factors. The characterization of the stress triaxiality under different elastic mixity factors shows that there exists the negative value for the stress triaxiality under mixed conditions as mixity factor are less than 1 . The negative region is unsymmetrical along the crack line for pure mode II case. With the increase of the remote elastic mixity factor, the negative region decrease to zero as the remote mixity factor approaches to 1 .

\subsection{Blunting effect under different T-stress level}

To investigate the influence of $T$-stress on the blunted crack tip, the distribution of opening stress in angular direction under different level of $T$-stress are figured out in Fig. 17. It can be found that the whole opening stress heightens with the increase of $T$-stress for all these mixity factors. It reveals that the stress level also can be influenced by remote $T$-stress for blunted crack tip field. It should be pointed out that the most significant region that influenced by the $T$-stress locates at the upper part of the crack tip field. For the lower part of the crack tip field, the opening stress seems to be not affected that much. Compared with the sharp crack model presented in Section 4.1, the opening stress level here is higher.

As discussed above, the blunting effect can affect the opening stress in ten times of the radius of crack tip. Hence, the opening stress along the crack line within a range of blunting effect region has been given in Fig. 18. The peak value locations for these different $T$-stress levels are almost not influenced, i.e. near the length of the crack tip radius. The opening stress heightens with the increase of the $T$-stress level. In blunted effect region, the opening stress become larger as the increase of the mixity factors though they are under the same effective SIF at far field. 


\subsection{Creep strain distribution and crack tip deformation under finite strain deformation}

The accumulation of creep strain can cause the damage of the crack front which can lead to the formation of the crack and may cause the failure of the structure eventually. The distribution of creep strain under different remote mixity factors are given in Fig. 19. It can be seen that the maximum value of equivalent creep strain (CEEQ) under mode II case has the largest creep strain compared with the other conditions. The peak value of the maximum strain decrease with the increase of remote elastic mixity factors. However, the locations of maximum CEEQ present differently with a variation from $-30^{\circ}$ at mode II case to about $\pm 90^{\circ}$ at mode I case. It can be seen that the blunting effect is easy to be understood as the accumulation of CEEQ is the smallest along the crack line.

The distribution of CEEQ under different $T$-stress levels for various remote elastic mixity factors, i.e. $0.3,0.5$ and 1.0 , are presented in Fig. 20. It can be seen that the CEEQ are surely related with the remote $T$-stress level. The high level of $T$-stress will lead to higher level of CEEQ, and the decrease of $T$-stress level will also lead to the decrease of CEEQ. With the decrease of remote elastic mixity factor, the whole level of CEEQ decreases.

As shown in Figs. 19 and 20, the extent for accumulation of creep strain is dependent on different remote elastic mixity factors. Under the same level of effective SIF, the pure mode II case has the higher creep strain level compared with the other mixity factors. It implies that the crack initiation for mode II case will be much earlier than that of mode I case though they are under the same loading level. It can be seen that the pure mode II case (shown as Fig. 21(a)) presents the sharpening effect at the upper flank of the crack. However, the sharpening effect becomes weaker and weaker as the crack mode approaches to pure mode I case (shown as Fig. 21(e)). It means that the crack deformation form of pure mode II may be dangerous as the sharpening effect can accelerate the damage process compared with that of mode I case. This phenomena presented here has been observed in experimental work given by Poquillon et al. [44].

\section{Concluding remarks}

As the Part I of this paper, the dominance of $C(t)$ of mixed mode creep crack under transient creep is presented and discussed. According to the investigations carried out in this paper, the following conclusions are obtained:

(1) For the transient creep, $C(t)$-integral is related with the level of effective SIF. The influence of remote elastic mixity factor on near field of mixed type creep crack is presented. With the increase of the remote elastic mixity factor, the maximum value of opening stress heightens with the rise of remote elastic mixity factor. Furthermore, the larger or lower $T$-stress level can lead to the significant influence on the mixed mode type crack tip field. The $T$-stress can also influence the creep zone remarkably under transient creep.

(2) The negative $T$-stress can increase the loss dominance of $C(t)$, on the contrary, the positive $T$-stress can decrease the loss dominance of $C(t)$ for mixed mode creep crack under transient regime. The relations of remote elastic mixity factors and creep mixity factors are nonlinear. With the definition of $Q^{\prime}$ and $Q^{*}$, it can be found that $Q^{\prime}$ relies on the distance away from crack tip and the positive $T$-stress will cause higher constraint level compared with that of negative $T$ stress. However, $Q^{*}$ defined in MTS direction are independent on distance away from crack tip though they have a smaller value than that of corresponding $Q^{*}$.

(3) The stress triaxiality is independent on distance away from crack tip only under these conditions where mode II loading dominants most for sharp crack. There is also the radial-distance independent region for blunted crack under the condition that the mode II loading favours most. Moreover, the negative $T$-stress can reduce the stress triaxiality and positive $T$-stress can improve the stress triaxiality. The difference between the stress triaxiality enlarges with the rise of remote elastic mixity factor though the $T$-stress level is the same.

(4) Comparisons between the sharp crack tip and blunted crack tip are made. It can be found that the influenced region is around ten times of radius for blunted crack tip. There is no difference if the radius exceeds ten times of the crack tip radius. The peak value of the opening stress for blunted crack tip field locates at the one times of crack tip radius. The maximum value of equivalent creep strain obtains under pure mode II case, and minimum value of equivalent creep strain presents under pure mode I case. There exists the sharpening effect for mode II case which implies the mode II case maybe much dangerous than that of mode I case as the sharpening effect will accelerate the creep damage. The sharpening effect becomes weaker and weaker if the mixity factor decreases, and vanishes under mode I case where the blunting effect prefers.

The work presented in this paper could promote the understanding of the mixed I/II creep crack tip field under transient condition from numerical side, and experimental work will be carried out in further investigations.

\section{Acknowledgement}

This work was supported by China Postdoctoral Science Foundation (No. 2019M650403) and the National Natural Science Foundation of China (Grant Nos. 11672009 and 11672147).

\section{Appendix A}

Assuming that a structure containing a mixed mode type crack under a constant load at the creep time $t=0$, the near tip of the crack tip can be characterized by $J$-integral at this moment as below

$J=J_{\mathrm{I}}+J_{\mathrm{II}}+C(t) t=\frac{K_{\mathrm{I}}^{2}+K_{\mathrm{II}}^{2}}{E^{\prime}}+C(t) t$

where $E^{\prime}=E$ under plane stress condition and $E^{\prime}=E /\left(1-v^{2}\right)$ for plane strain condition, $E$ here is the Young's modulus. If the creep time is long enough, $C(t)$ approaches to $C^{*}$. According to Riedel and Rice [42], there exists the following relations based on the assumption that the strain rate field is proportional to the time.

$\varepsilon_{i j}=\dot{\varepsilon}_{i j} \frac{\int_{0}^{t}[C(\tau)]^{n /(n+1)} \mathrm{d} \tau}{[C(t)]^{n /(n+1)}}$

Under the mixed mode type creep crack, this above deduce is the same as the mode I case as they presents the same singularity. Regardless of the mixed type, the $J$-integral can be presented as

$J=[C(t)]^{1 /(n+1)} \int_{0}^{t}[C(\tau)]^{n /(n+1)} \mathrm{d} \tau$ 
By differentiating the Eq. (A3), there can be derived as below

$\frac{\mathrm{d} J}{\mathrm{~d} t}=C(t)+\frac{J}{(n+1) C(t)} \frac{\mathrm{d} C(t)}{\mathrm{d} t}$

The following relations can be obtained as

$C(t)=\frac{J^{n+1}}{(n+1)} \int_{0}^{t} J^{n} \mathrm{~d} t$

Substituting Eq. (A1) into Eq. (A5), the following formulae can be obtained.

$C(t)=C^{*}\left\{\frac{\left(1+E^{\prime} C^{*} t /\left(K_{\mathrm{I}}^{2}+K_{\mathrm{II}}^{2}\right)\right)^{n+1}}{\left(1+E^{\prime} C^{*} t /\left(K_{\mathrm{I}}^{2}+K_{\mathrm{II}}^{2}\right)\right)^{n+1}-1}\right\}$

For transient creep time, $C(t)$ can be presented as

$C(t)=\frac{K_{\mathrm{I}}^{2}+K_{\mathrm{II}}^{2}}{(n+1) E^{\prime} t}=\frac{K_{\mathrm{eff}}^{2}}{(n+1) E^{\prime} t}$

Thus, transition time under mixed I/II loading can be obtained as

$t_{\mathrm{T}}=\frac{K_{\mathrm{I}}^{2}+K_{\mathrm{II}}^{2}}{(n+1) E^{\prime} C^{*}}=\frac{K_{\mathrm{eff}}^{2}}{(n+1) E^{\prime} C^{*}}$

\section{Appendix B. Supplementary material}

Supplementary data to this article can be found online at https://doi.org/10.1016/j.tafmec.2019.102314.

\section{References}

[1] P. Budden, R. Ainsworth, The effect of constraint on creep fracture assessments, Int. J. Fract. 87 (1997) 139-149.

[2] Y.J. Chao, X.K. Zhu, L. Zhang, Higher-order asymptotic crack-tip fields in a powerlaw creeping material, Int. J. Solids Struct. 38 (2001) 3853-3875.

[3] G.A. Qian, W.S. Lei, A statistical model of fatigue failure incorporating effects of specimen size and load amplitude on fatigue life, Philos. Mag. (2019) 1-37.

[4] G.A. Qian, W.S. Lei, Z. Yu, F. Berto, Statistical size scaling of breakage strength of irregularly-shaped particles, Theor. Appl. Fract. Mech. 102 (2019) 51-58.

[5] G.A. Qian, W.S. Lei, L. Peng, Z. Yu, M. Niffengger, Statistical assessment of notch toughness against cleavage fracture of ferritic steels, Fatigue Fract. Eng. Mater. Struct. 41 (2018) 1120-1131.

[6] Y.W. Dai, D.H. Liu, Y.H. Liu, Mismatch constraint effect of creep crack with modified boundary layer model, J. Appl. Mech. 83 (2016) 031008.

[7] Y.W. Dai, Y.H. Liu, Y.J. Chao, Higher order asymptotic analysis of crack tip fields under mode II creeping conditions, Int. J. Solids Struct. 125 (2017) 89-107.

[8] M. Xiang, Z. Yu, W.L. Guo, Characterization of three-dimensional crack border fields in creeping solids, Int. J. Solids Struct. 48 (2011) 2695-2705.

[9] M.J. Xiang, W.L. Guo, Formulation of the stress fields in power law solids ahead of three-dimensional tensile cracks, Int. J. Solids Struct. 50 (2013) 3067-3088.

[10] G.Z. Wang, X.L. Liu, F.Z. Xuan, S.T. Tu, Effect of constraint induced by crack depth on creep crack-tip stress field in CT specimens, Int. J. Solids Struct. 47 (2010) $51-57$.

[11] M. Tabuchi, J. Ha, H. Hongo, T. Watanabe, Yokobori Jr, Experimental and numerical study on the relationship between creep crack growth properties and fracture mechanisms, Metall. Mater. Trans. A 35 (2004) 1757-1764.

[12] B. Nguyen, P. Onck, E. Van Der Giessen, On higher-order crack-tip fields in creeping solids, J. Appl. Mech. 67 (2000) 372-382.

[13] K. Nikbin, Justification for meso-scale modelling in quantifying constraint during creep crack growth, Mater. Sci. Eng. A 365 (2004) 107-113.

[14] J.Z. He, G.Z. Wang, S.T. Tu, F.Z. Xuan, Effects of side-groove depth on creep cracktip constraint and creep crack growth rate in C (T) specimens, Fatigue Fract. Eng. Mater. Struct. 41 (2) (2018) 260-272.

[15] C.F. Shih, Small-scale yielding analysis of mixed mode plane-strain crack problems, ASTM STP 560 (1974) 187-210.

[16] M.F. Symington, C.F. Shih, M. Ortiz, Tables of Plane Strain Mixed-Mode Plastic Crack Tip Fields, Brown University Division of Engineering, 1988.

[17] S. Aoki, K. Kishimoto, T. Yoshida, M. Sakata, A finite element study of the near crack tip deformation of a ductile material under mixed mode loading, J. Mech. Phys. Solids 35 (1987) 431-455.

[18] Z. Du, C. Betegon, J. Hancock, J dominance in mixed mode loading, Int. J. Fract. 52 (1991) 191-206.

[19] Y.A. Roy, R. Narasimhan, J-dominance in mixed mode ductile fracture specimens, Int. J. Fract. 88 (1997) 259-279.

[20] Y.A. Roy, R. Narasimhan, A finite element investigation of the effect of crack tip constraint on hole growth under mode I and mixed mode loading, Int. J. Solids Struct. 36 (1999) 1427-1447.

[21] M.A. Sutton, X. Deng, F. Ma, Newman Jr, M. James, Development and application of a crack tip opening displacement-based mixed mode fracture criterion, Int. J. Solids Struct. 37 (2000) 3591-3618.

[22] M. Ayatollahi, D. Smith, M. Pavier, Crack-tip Constraint in mode II deformation, Int. J. Fract. 113 (2002) 153-173.
[23] N.P. O'Dowd, C.F. Shih, Family of crack-tip fields characterized by a triaxiality parameter-I. Structure of fields, J. Mech. Phys. Solids 39 (1991) 989-1015.

[24] H. Subramanya, S. Viswanath, R. Narasimhan, A three-dimensional numerical study of mixed mode (I and II) crack tip fields in elastic-plastic solids, Int. J. Fract. 136 (2005) 167-185.

[25] S. Yang, Y.J. Chao, M.A. Sutton, Complete theoretical analysis for higher order asymptotic terms and the HRR zone at a crack tip for Mode I and Mode II loading of a hardening material, Acta Mech. 98 (1993) 79-98.

[26] V. Tvergaard, Effect of pure mode I, II or III loading or mode mixity on crack growth in a homogeneous solid, Int. J. Solids Struct. 47 (2010) 1611-1617.

[27] N. Hallbäck, N. Jönsson, T-stress evaluations of mixed mode I/II fracture specimens and T-effects on mixed mode failure of aluminium, Int. J. Fract. 76 (1995) 141-168.

[28] Y.J. Chao, S. Liu, On the failure of cracks under mixed-mode loads, Int. J. Fract. 87 (1997) 201-223.

[29] V.N. Shlyannikov, A. Tumanov, Characterization of crack tip stress fields in test specimens using mode mixity parameters, Int. J. Fract. 185 (2014) 49-76.

[30] V.N. Shlyannikov, A. Tumanov, A.P. Zakharov, The mixed mode crack growth rate in cruciform specimens subject to biaxial loading, Theor. Appl. Fract. Mech. 73 (2014) 68-81.

[31] J. Brockenbrough, C.F. Shih, S. Suresh, Transient crack-tip fields for mixed-mode power law creep, Int. J. Fract. 49 (1991) 177-202.

[32] E.P. Busso, D.W. Dean, D. Linkens, On the effects of loading conditions and geometry on time-dependent singular crack tip fields, Eng. Fract. Mech. 50 (1995) 231-247.

[33] A.P. Gordon, D.L. McDowell, Mixed mode loading of an interface crack between graded creeping solids, J. Pressure Vessel Technol. 126 (2004) 478-484.

[34] Y.W. Dai, Y.H. Liu, H.F. Chen, Numerical investigations on the effects of T-stress in mode I creep crack, Int. J. Comput. Meth. (2018) 1841002.

[35] Y.W. Dai, Y.H. Liu, H.F. Chen, Influences of T-Stress on constraint effect in mismatched modified boundary layer model for creep crack, Proceedings of ASME Pressure Vessels and Piping Conference 2016, (2016) V003T03A072.

[36] F.H. Norton, The Creep of Steel at High Temperatures, McGraw-Hill Book Company Incorporated, 1929.

[37] J.L. Bassani, D.E. Hawk, A. Saxena, Evaluation of the Ct parameter for characterizing creep crack growth rate in the transient regime, Nonlinear Fracture Mechanics: Volume I Time-Dependent Fracture, ASTM International, 1988.

[38] Y.W. Dai, Higher order asymptotic solutions for cracks and V-notches in creeping solids: Theoretical analysis and engineering implications, $\mathrm{PhD}$ Thesis, Tsinghua University, Beijing, 2018 (in Chinese).

[39] Y.G. Matvienko, Maximum average tangential stress criterion for prediction of the crack path, Int. J. Fract. 176 (2012) 113-118.

[40] L. Zhao, L. Xu, Y. Han, H. Jing, Two-parameter characterization of constraint effect induced by specimen size on creep crack growth, Eng. Fract. Mech. 143 (2015) $121-137$.

[41] Y.G. Matvienko, V.N. Shlyannikov, N.V. Boychenko, In-plane and out-of-plane constraint parameters along a three-dimensional crack-front stress field under creep loading, Fatigue Fract. Eng. Mater. Struct. 36 (1) (2013) 14-24.

[42] Riedel, Rice, Tensile cracks in creeping solids, West Conshohocken, PA: ASTM STP 700, 1980, pp. 112-130.

[43] S.A. English, N.K. Arakere, Effects of the strain-hardening exponent on two-parameter characterizations of surface-cracks under large-scale yielding, Int. J. Plast. 27 (6) (2011) 920-939.

[44] D. Poquillon, M. Cabrillat, A. Pineau, Mode II creep crack initiation in 316 LN stainless steel: experiments and modelling, Mater. High Temp. 16 (1999) 99-107. 